\title{
1 Are surface temperature and chlorophyll in a large deep lake 2 related? An analysis based on satellite observations in synergy with hydrodynamic modelling and in-situ data
}

6 Damien Bouffard $^{1 *}$, Isabel Kiefer ${ }^{2}$, Alfred Wüest ${ }^{1,2}$, Stefan Wunderle ${ }^{3}$, Daniel Odermatt ${ }^{4}$,

7 (1) Eawag, Swiss Federal Institute of Aquatic Science and Technology, Surface Waters -

8 Research and Management, Seestrasse 79, CH-6047 Kastanienbaum, Switzerland

$9{ }^{(2)}$ Physics of Aquatic Systems Laboratory, Margaretha Kamprad Chair, EPFL-ENAC-IEE-

10 APHYS, CH-1015 Lausanne, Switzerland

$11{ }^{(3)}$ Remote Sensing Research Group, Institute of Geography, Hallerstrasse 12, University of Bern, 12 CH- 3012 Bern, Switzerland

$13{ }^{(4)}$ Odermatt and Brockmann GmbH, Stampfenbachstrasse 57, CH-8006 Zürich, Switzerland 14 15

$16{ }^{*}$ Correspondence to: Damien Bouffard (damien.bouffard@eawag.ch).

This document is the accepted manuscript version of the following article:

Bouffard, D., Kiefer, I., Wüest, A., Wunderle, S., \& Odermatt, D. (2018). Are surface temperature and chlorophyl1 in a large deep lake related? An analysis based on satellite observations in synergy with hydrodynamic modelling and in-situ data. Remote Sensing of Environment, 209, 510-523. https://doi.org/10.1016/j.rse.2018.02.056

This manuscript version is made available under the CC-BY-NC-ND 4.0

license http://creativecommons.org/1icenses/by-nc-nd/4.0/ 
19 Abstract. Phytoplankton growth depends on various factors, and primarily on nutrient

20 availability, light and water temperature, whose distributions are largely controlled by

21 hydrodynamics. Our main objective is to analyse the link between spatial and temporal

22 variability of surface water temperature and algal concentration in a large lake by means of

23 remote sensing and hydrodynamic modelling. We compare ten years of satellite images showing

24 chlorophyll concentrations and surface water temperature of Lake Geneva. Our observations

25 suggest different correlations depending on the season. Elevated chlorophyll concentrations in

26 spring are correlated with warmer zones. But, in summer, higher chlorophyll concentrations are

27 observed in colder zones. We show with a three-dimensional hydrodynamic model that the

28 spatial variability of the surface water temperature reflects the upwelling and downwelling zones

29 resulting from wind forcing. In springtime, nearshore downwellings induce locally increased

30 surface temperature and stratification, which are associated with high chlorophyll concentration.

31 In summertime, colder surface temperature area, often interpreted as transient upwellings,

32 represents the thermal surface signature of wind-induced basin-scale internal waves, bringing

33 either nutrients or phytoplankton from deeper layers to the surface. Our study suggests the latter

34 to be the dominant process, with the basin-scale internal wave activity and associated transient

35 summertime upwellings and downwellings having little net effects on the algal concentration.

36 This study finally demonstrates the necessity to connect remote sensing retrievals and three-

37 dimensional hydrodynamic modelling to properly understand the dynamic of the lake

38 ecosystems. 


\section{Introduction}

40 Photosynthetic growth of phytoplankton in surface waters depends mainly on light, temperature,

41 and nutrients (Reynolds, 2006). The seasonal and inter-annual variability of phytoplankton

42 dynamics is the result of complex interactions of temporally variable abiotic and biotic

43 parameters and mechanisms (Behrenfeld and Boss, 2014; Sommer et al., 2012) also depending

44 on other processes, such as competition or grazing. In temperate regions, seasonal stratification

45 governs these processes to a large extent, by limiting the upward flux of hypolimnetic nutrients

46 to the photic surface layer of lakes (epilimnion), where light is usually abundant in oligo- to

47 mesotrophic lakes (Sharples et al., 2001; Watanabe et al., 2016). During the stratified seasons,

48 nutrients are consumed in the photic surface layer (Sommer et al., 2012), and only limited

49 phytoplankton growth occurs after the first spring bloom, while phytoplankton growth

50 progressively moves to deeper layers (Barbiero and Tuchman, 2004; Dokulil and Teubner,

51 2012).

52 In spring, the increasing lake temperature governs phytoplankton growth by two

53 mechanisms: (i) acceleration of the physiological processes, such as nutrient uptake, growth and

54 respiration (Berger et al., 2010; Goldman and Carpenter, 1974), and (ii) development of the

55 thermal stratification of the water column (Diehl et al., 2002; Berger et al., 2010).

56 In summer, phytoplankton growth is often nutrient-limited. Long lasting coastal

57 upwelling has been identified as an important source of nutrients, when transported from the

58 deep water to the upper photic layer (Mackas et al., 1985). As a result, most of the primary

59 production in the global ocean takes place in upwelling regions (Falkowski et al., 1998; Gruber

60 et al., 2011). In lakes, with the exception of very large ones like Lake Baikal (Troitskaya et al.,

61 2015), upwelling of cold and nutrient-rich deep water are mostly wind-induced and are therefore 
62 transient (Steissberg et al., 2005). MacIntyre and Jellison (2001) observed in a medium-sized

63 lake (where Coriolis forces remain negligible) that strong wind-induced upwelling can increase

64 nutrient upward flux and favour phytoplankton growth. Yet, the inverse effect was also observed.

65 After a major storm event, cold hypolimnetic water in Lake Constance was correlated with

66 significantly lower chlorophyll- $a$ concentrations (CHL) than the warm, epilimnetic water (Rinke

67 et al., 2009).

All the above-mentioned processes are associated with lateral variability in the dynamical

69 behaviour of phytoplankton growth. Yet, lake monitoring strategies typically focus on sampling

70 ecological parameters at the lake centre or at the deepest point, thereby neglecting spatial

71 variability and littoral processes (Pomati et al., 2011). Traditional attempts to capture the lateral

72 variability in phytoplankton horizontal dynamics require extensive in-situ measurements

73 (Thackeray et al., 2004). Remote sensing applications for lake water composition (Giardino et

74 al., 2001; Odermatt et al., 2012a) and lake surface water temperature (LSWT; (Oesch et al.,

75 2005) have opened new perspectives for monitoring spatial and temporal water quality

76 dynamics. However, satellite measurements remain limited in depth, i.e. to the first micrometers

77 for LSWT and to roughly Secchi depth for the least attenuated wavelengths of reflected solar

78 irradiation. The depth limited information and their temporal stochasticity call for an integration

79 of both in-situ and remote sensing data into numerical models to constrain lake system studies.

80 While this approach has often been applied in oceanography, examples of integration of in-situ,

81 remote sensing and model data remain scarce in inland waters (Curtarelli et al., 2015; Wynne et

82 al., 2013).This study examines the inter-seasonal relationships between satellite-observed LSWT

83 and CHL in Lake Geneva. Data from the Advanced Very High Resolution Radiometer

84 (AVHRR) on the US National Oceanic and Atmospheric Administration (NOAA) satellites are 

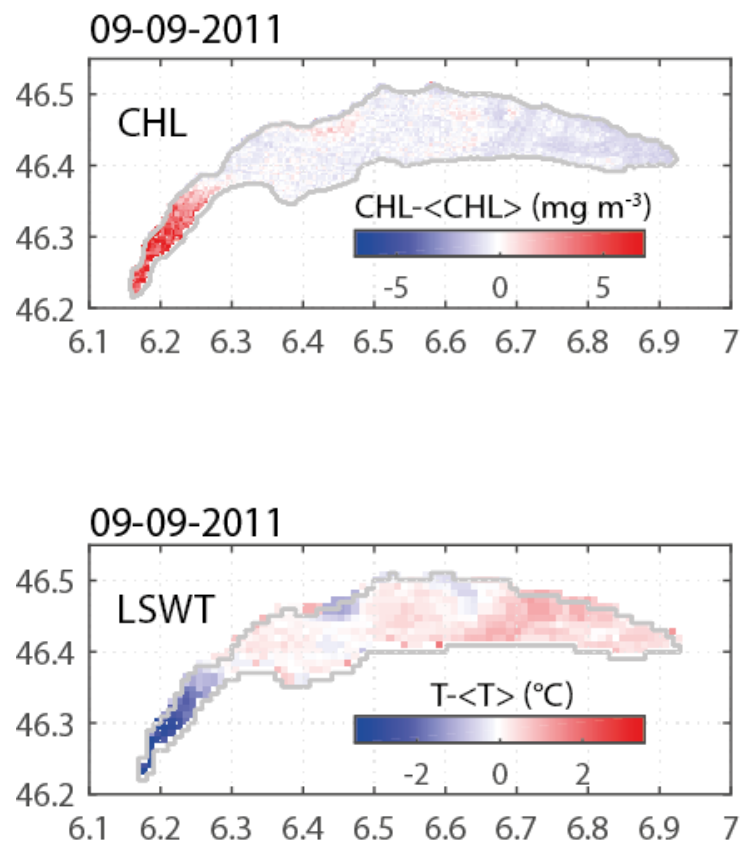

used for LSWT, which is a relative indicator for physical phenomena, such as stratification and upwelling. CHL is derived from the MEdium Resolution Imaging Spectrometer (MERIS) full resolution images on the European Space Agency Environmental Satellite (ENVISAT). The investigations make use of all available data pairs (e.g. AVHRR and MERIS data) acquired during the ten years of ENVISAT operations (17 $7^{\text {th }}$ May 2002 to $8^{\text {th }}$ April 2012).
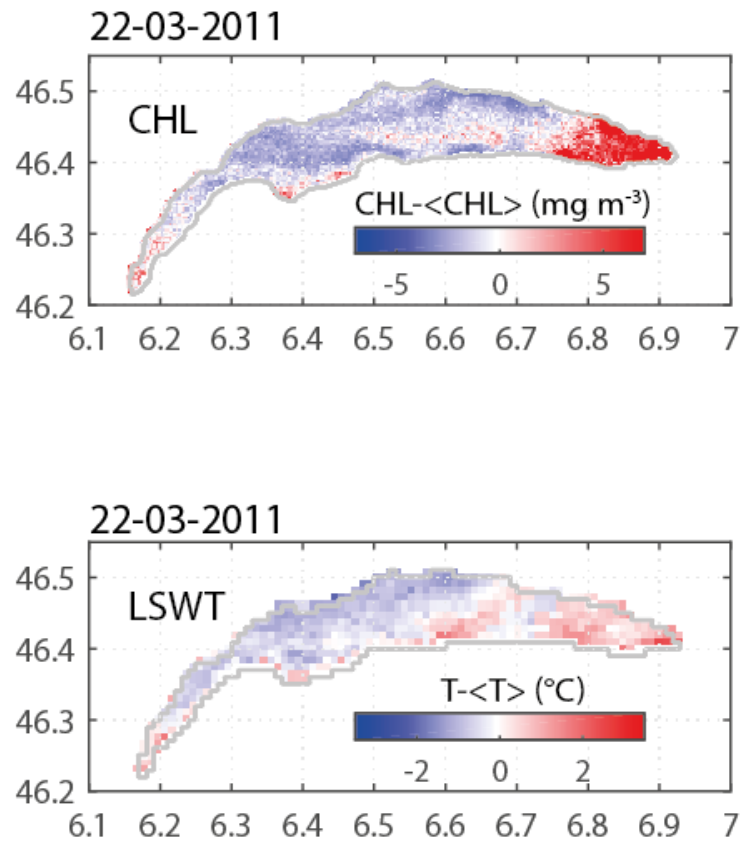

Figure 1. Differences of chlorophyll (CHL) and lake surface water temperature (LSWT) relative to their spatial averages for two same-day scenes, one in spring (right) and one in autumn (left) 2011. Both show spatial correlation between CHL and LSWT.

Based on intriguingly correlated remotely sensed CHL and LSWT image pairs (Figure 1), we formulate two season specific hypotheses on physical and biological in Lake Geneva. First, in spring, we expect a positive relationship between phytoplankton growth and temperature; or, implicitly, dependent on the stability of the water column. We expect that phytoplankton growth is enhanced in downwelling zones, where warm surface water is converging. Second, in summer and fall, and after the build-up of the seasonal thermocline and algae growth-induced surface 
100 nutrient depletion, phytoplankton growth becomes nutrient-limited. We expect that

101 phytoplankton growth is enhanced in upwelling zones.

102 These hypotheses are investigated using a spatial autocorrelation indicator (Moran's $I$ ) for

103 satellite data pairs. Results are analysed with respect to in-situ data such as depth-dependent

104 annual phosphorus and CHL concentrations and the short-term spatio-temporal change in the

105 thermal structure as inferred from a three-dimensional (3D) hydrodynamic model.

106

107

108

109

110

111

112

113

\section{Study area and data}

\subsection{Lake Geneva study site}

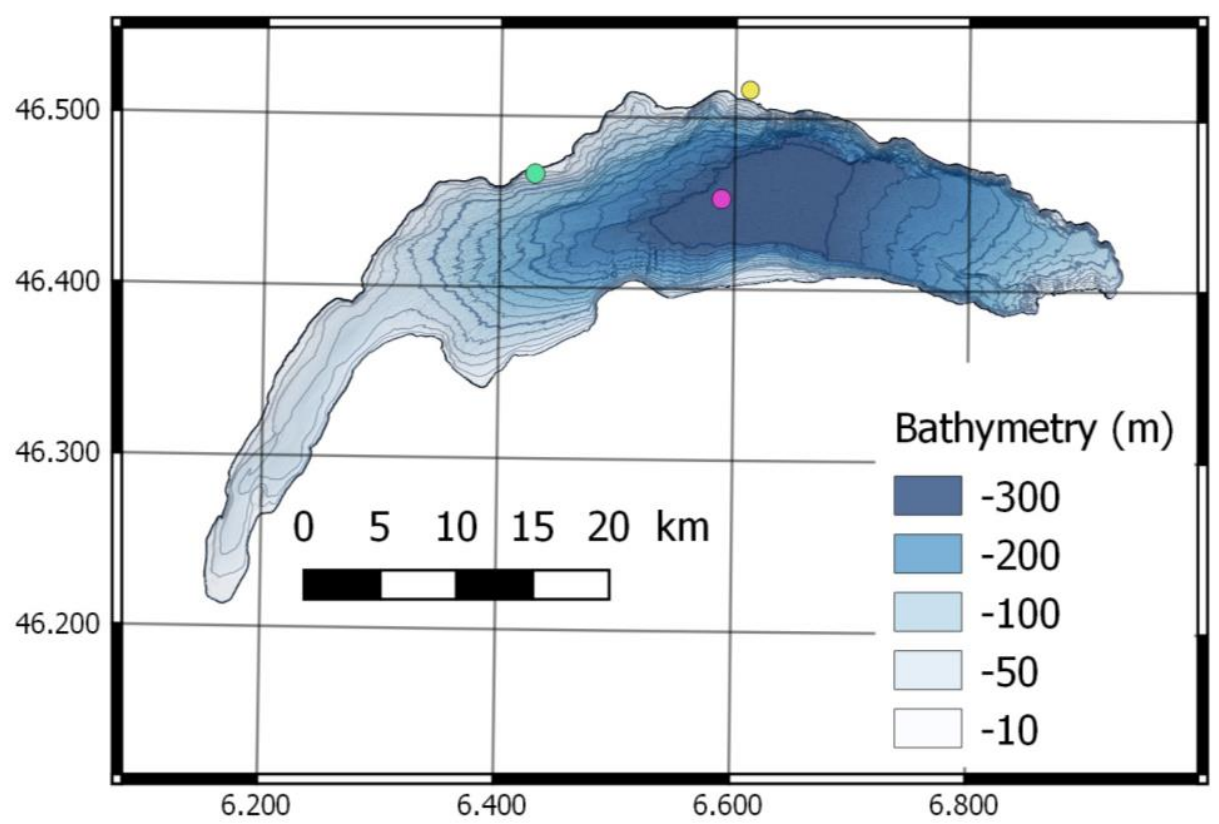

Figure 2. Map of Lake Geneva with locations SHL2 (pink), Buchillon (green) and Pully (yellow). In-situ CHL calibration samples are regularly taken at SHL2. Temperatures measured at Buchillon and at SHL2 have been used for calibrating the three-dimensional Delft3D-Flow model. $20 \mathrm{~m}$ isolines are shown.

Lake Geneva (Figure 2) is a perialpine lake situated at an altitude of $372 \mathrm{~m}$ above sea

114 level with a surface area, a total volume and a maximum depth of $580 \mathrm{~km}^{2}, 89 \mathrm{~km}^{3}$ and $309 \mathrm{~m}$, 
115 respectively. Its two main basins, the Grand Lac ("large lake") and the Petit Lac ("small lake")

116 differ in average depth and volume (172 $\mathrm{m}$ and $96 \%$ vs. $41 \mathrm{~m}$ and $4 \%$ ). Lake Geneva is a warm

117 monomictic lake with seasonal convective mixing reaching deepest typically in late February or

118 early March. Depending on temperatures and wind intensities during winter, deep convective

119 mixing usually does not extend over the entire water column (Rimet et al., 2009; Schwefel et al.,

120 2016). Between 2002 and 2012, complete mixing took place only in March 2005, 2006 and

121 2012, redistributing nutrients and oxygen over the entire water column.
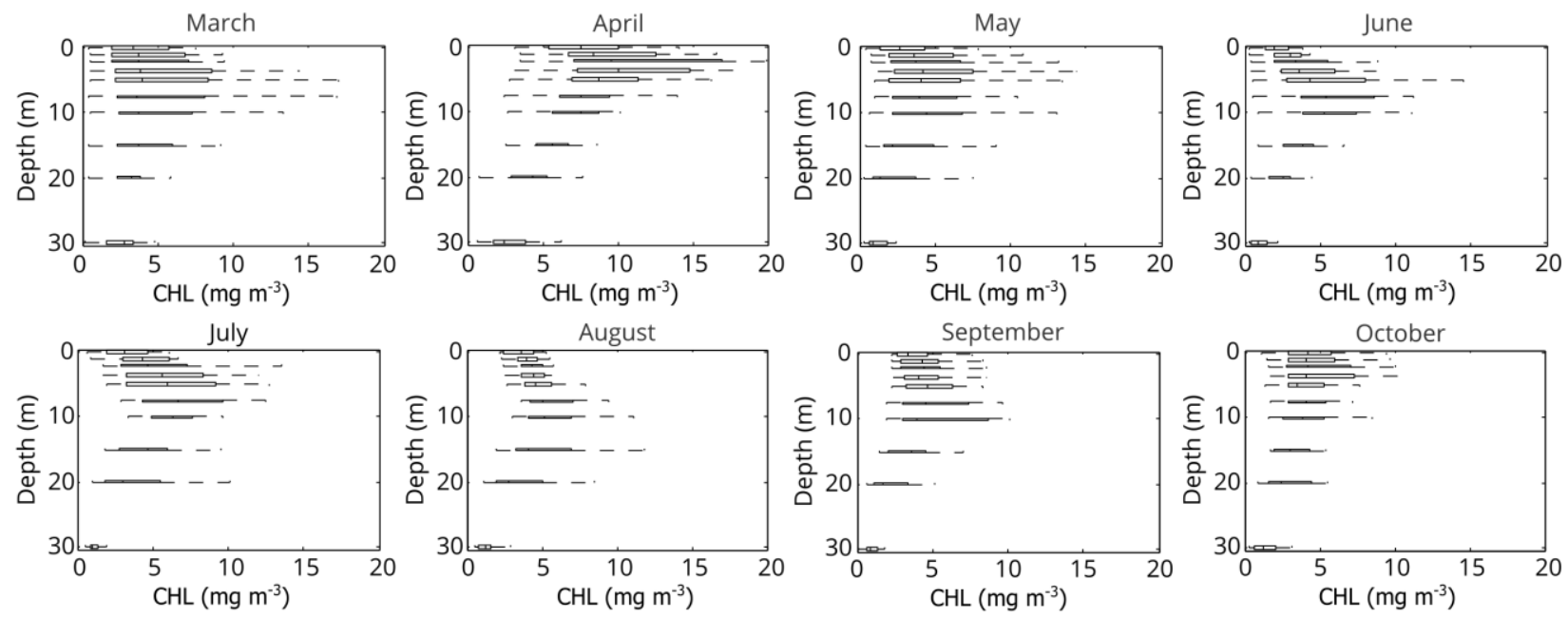

Figure 3. Concentrations of CHL during the productive season (March to October) in Lake Geneva. The data shown is based on bi-monthly in-situ measurements at SHL2 (Figure 2) for the period 2002-2012. Boxplot with whiskers length 1.5 ( $\pm 2.7 \sigma)$; outliers are not shown.

127 strongest blooms in spring. Spring CHL maxima are located near the surface, while later in the

128 season they are found deeper (Figure 3). Phosphorus concentrations are typically high at the

129 beginning of the productive season (Figure 4), currently at $\sim 18 \mathrm{mg} \mathrm{m}^{-3}$, following the winter

130 deep mixing of the water column. However, once the biological activity has started in spring,

131 these nutrients are depleted in the photic surface layer (Figure 4). Spring time lake warming and

132 subsequent onset of stratification cut off the light-abundant surface layer from the nutrient-richer 
133 deeper layers. The nutrient depletion typically extends down to $35-50 \mathrm{~m}$ in Lake Geneva.

134 Deeper layers maintain considerably higher average phosphate concentrations throughout the

135 year (Figure 4).
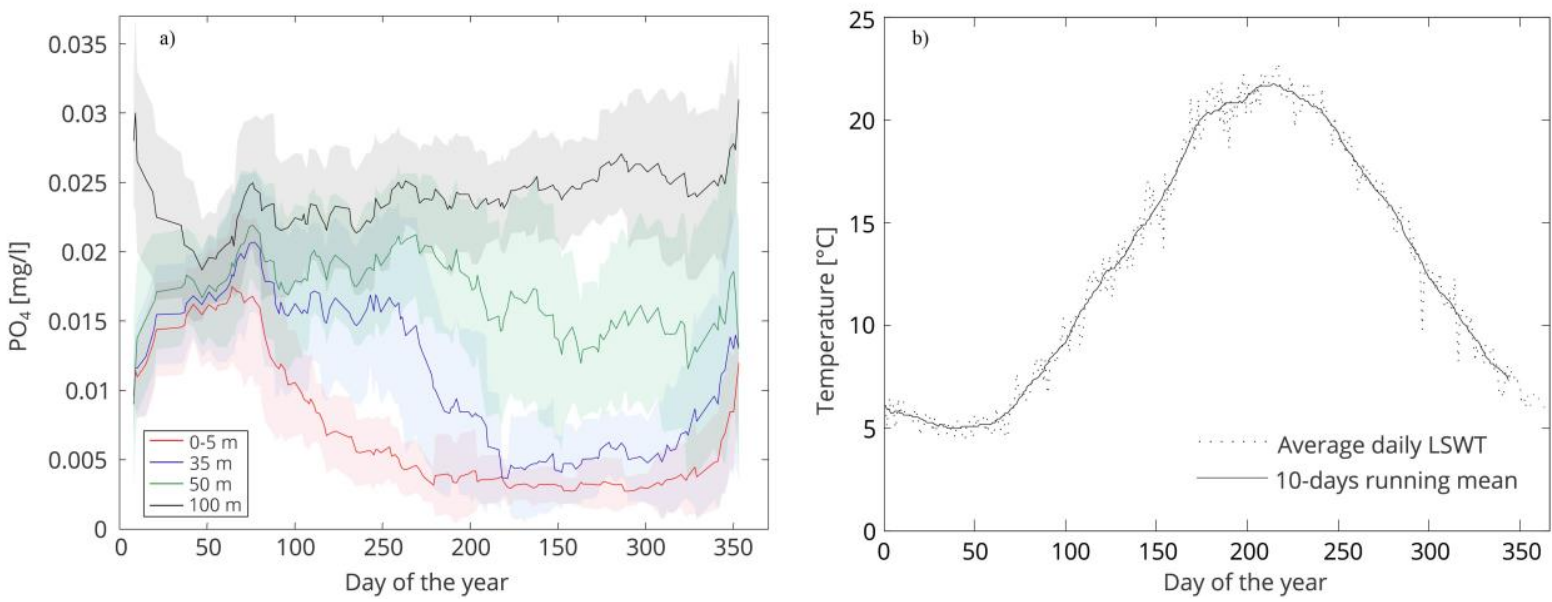

137 Figure 4. a) Average annual cycle of phosphate concentrations at different depths (0-5 m, $35 \mathrm{~m}$, $13850 \mathrm{~m}, 100 \mathrm{~m})$ for 2002 to 2010. Bold line: average per day of the year; shaded area: $95 \%$ 139 confidence interval. b) Average annual cycle of LSWT, computed from horizontally-averaged 140 AVHRR satellite images (2002-2012). Dashed line: average per day of the year; solid line: 10 141 days running mean.

\section{2.2 Satellite data}

\subsubsection{Advanced Very High Resolution Radiometer data}

Satellite images from the AVHRR sensor are routinely acquired by the Remote Sensing

Research Group at the University of Bern (Riffler et al., 2015). The data is available from 1989 onwards at $1.1 \mathrm{~km}$ spatial resolution (at nadir) and temporal resolutions between one and ten images per 24 hours (Hüsler et al., 2011). In order to guarantee data homogeneity and continuity over the different AVHRR sensors of the NOAA and the European Meteorological Operational

149 (MetOp) polar orbiting satellites, the data reprocessing comprehends radiometric time- and 150 sensor-dependent calibration, precise geolocation, atmospheric correction, cloud masking and 
151 time-series specific corrections (Oesch et al., 2005). Data from the satellites MetOp-A, NOAA

15214 and NOAA 16 to 19 from 2002 to 2012 are used in this study. LSWT retrieval methods,

153 calibration, and validation are discussed in detail in Oesch et al. (2005) and Riffler et al. (2015).

154 Biases between AVHRR-derived LSWT and in-situ measurements are in the range of -0.5 to

$155+0.6{ }^{\circ} \mathrm{C}$ and root mean square errors are 1.0 to $1.6^{\circ} \mathrm{C}$ (Riffler et al., 2015). The difference

156 between satellite-derived and in-situ measurements is mainly based on the fact, that a satellite

157 sensor retrieves only the signal from the upper most micrometre (skin temperature), whereas in-

158 situ devices are mounted in deeper layers (bulk temperature). A skin-to-bulk correction using

159 wind speed is applied to convert LSWT to in-situ and model bulk temperature. As shown by

160 Minnett et al. (2011), Wilson et al. (2013) and others, the bulk temperature can differ by up to

161 several K depending on meteorological conditions and water stratification. Therefore, skin-to-

162 bulk conversion is needed considering the different radiative processes between lake water and

163 atmosphere as well as mixing in the uppermost water layer. This correction reduces the bias to

$164 \sim 0.2{ }^{\circ} \mathrm{C}$ (Riffler et al., 2015). Observations are averaged when more than one image per day is

165 available. Cloud masking is an essential step to guarantee the retrieval of surface temperature

166 unaffected by clouds or cloud shadows. Cloud detection is mainly based on CASPR (Cloud And

167 Surface Parameter Retrieval; Key, 2002) and cloud shadow is masked using the method of

168 Simpson and Stitt (1998). Due to the limited spectral resolution of the AVHRR sensor (only

169 three channels for VIS-NIR spectra and two channels for the thermal infrared) not all clouds

170 effects are detected. Consequently, a quality control procedure is applied to remove erroneous

171 pixels. This procedure includes spatial tests in a $3 \times 3$ surrounding, thresholds of reflectance

172 values, temperature margins etc. Detailed information is given in Riffler et al. (2015) and Hüsler

173 et al. (2011). 


\subsubsection{MEdium Resolution Imaging Spectrometer data}

175

176

177

178

179

180

181

182

183

184

185

186

187

188

189

190

191

192

193

194

195

For the retrieval of CHL we use data acquired by the European Space Agency's (ESA)

Medium Resolution Imaging Spectrometer (MERIS) between June 2002 and April 2012. In its

default band configuration, MERIS measured radiance in 15 narrow spectral bands between 413

and $900 \mathrm{~nm}$. The MERIS L1B data was processed using the ESA Calvalus portal (Fomferra et

al., 2012) and dedicated methods for improved georectification (Bourg and Etanchaud, 2007),

smile effect correction (Bouvet and Ramoino, 2010), valid water pixel identification (Idepix,

Ruecas et al. (2014)) and CHL retrieval (FUB neural network; Schroeder et al. (2007)). The

resulting CHL maps were collocated in a regularly-spaced grid of $270 \mathrm{~m}$ cell size, and calibrated

and validated using 46 in-situ monitoring samples collected in Lake Geneva (Section 2.3.2)

when a MERIS image was acquired on the same day (Kiefer et al., 2015). Concentrations for the top $5 \mathrm{~m}$ of the water column are averaged as reference for comparison with $3 \times 3$ pixel averaged

CHL from MERIS.

The FUB algorithm performs water quality parameter retrieval using neural networks that were trained with radiative transfer simulations for bio-optical scattering and absorption properties in optically complex waters. The range of these simulations is up to $50 \mathrm{mg} \mathrm{m}^{-3} \mathrm{CHL}$, $50 \mathrm{~g} \mathrm{~m}^{-3} \mathrm{TSM}$ and $1 \mathrm{~m}^{-1} \mathrm{CDOM}$ and thus suitable for Lake Geneva. Such retrieval algorithms make use of the quantitative relationship between phytoplankton pigment absorption and CHL, which is subject to relatively large uncertainty (Odermatt et al., 2012b). Therefore, we recalibrated the CHL levels provided by the FUB algorithm with the gain and offset of a zero intercept forced linear regression $\left(\mathrm{R}^{2}=0.62\right.$; Kiefer et al., 2015). The RMSE after calibration is $2.3 \mathrm{mg} \mathrm{m}^{-3}$, which means that for Lake Geneva, the performance of the whole automatic 
196 processing is comparable to previous studies using visually selected cloud-free data and a much

197 smaller number of validation samples (Odermatt et al., 2010).

199 pixels. Four images were excluded as outliers due to extraordinarily high CHL, leaving 1234

200 applicable images, with up to 623 valid observations per grid cell. Grid cells with less than 300

201 valid observations are found along the shore due to occasional land and mixed pixel flagging.

202 They were removed entirely from further analysis (Kiefer et al., 2015).

203

204

205

206

207

208

209

210

211

212

213

214

215 Lake Geneva (CIPEL) at SHL2 (Figure 2) in the middle of the lake $\left(46.453{ }^{\circ} \mathrm{N}, 6.588^{\circ} \mathrm{E} ; 309 \mathrm{~m}\right.$

216 depth). Concentration of bio-available orthophosphates $\mathrm{PO}_{4}-\mathrm{P}$ was determined at each depth 
217 (Figure 4) and CHL (Figure 3) was extracted by spectrometric analysis from water samples in

218 the top $30 \mathrm{~m}$ (Leboulanger, 2003). Water temperature was also monitored by CIPEL on a

219 monthly to bimonthly basis in parallel to the water samples, with a multiparameter profiler.

220 Hourly temperature data were collected at the northern part of the Lake (Buchillon, WGS84

$22146.458^{\circ} \mathrm{N}, 6.399^{\circ} \mathrm{E}$; Figure 2 ) at $1 \mathrm{~m}$ and $36 \mathrm{~m}$ below the surface.

$222 \quad 2.4$ Model data

223 The hydrodynamics of Lake Geneva is simulated with the three-dimensional (3D)

224 Delft3D-Flow model version 4.0001. This model was already successfully applied to Lake

225 Geneva by Razmi et al. (2013, 2017). The model solves the Reynolds-Averaged Navier-Stokes

226 equation with the Boussinesq approximation (e.g. fluid incompressible with properties

227 decomposed into their temporal average and their fluctuating component). We use the k-epsilon

228 model as turbulence closure and run the model with a $30 \mathrm{~s}$ time step. We use a horizontal (Z-

229 grid) coordinate system with a varying horizontal grid of a resolution never exceeding $300 \mathrm{~m}$

230 horizontally and with the vertical layer thickness increasing from $0.25 \mathrm{~m}$ at the surface to $1 \mathrm{~m}$ at

$23150 \mathrm{~m}$ depth and $10 \mathrm{~m}$ at $300 \mathrm{~m}$ depth (100 layers). The model is forced by the regional

232 meteorological model COSMO-2 (MeteoSwiss) with a grid size of $2.2 \mathrm{~km}$. A validation example

233 of the hydrodynamic model using high resolution temperature data and data from acoustic

234 Doppler current profilers is shown in Appendix A. The surface temperature outputs from the

235 model are also compared with LSWT from AVHRR. One difficulty in modelling Lake Geneva is

236 the weak stratification in the deepest layers that are not necessarily mixed every winter

237 (Schwefel et al., 2016). This deep convective mixing remained challenging to reproduce

238 (Gaudard et al., 2017). To avoid any cumulative effects in modelling the thermal structure of

239 Lake Geneva, the model was restarted after each deep winter mixing with initial conditions 
240 based on observed temperatures from late-winter. In this study the effects of tributaries were

241 neglected. With a residence time of 11 years, the thermal structure and dynamics of the circulation is only

242 very locally affected by the tributaries (mostly the Rhône River). Moreover, the effects of the Rhône

243 River near the surface are very limited as the river is generally denser (high particle concentration and

244 cold temperature) than the lake surface water and plunge to greater depth (Bouffard and Perga, 2016;

245 Råman Vinnå et al., 2018).

246

$247 \quad 2.5$ Spatial correlation statistics

\subsubsection{Data-pairs of surface temperature and chlorophyll}

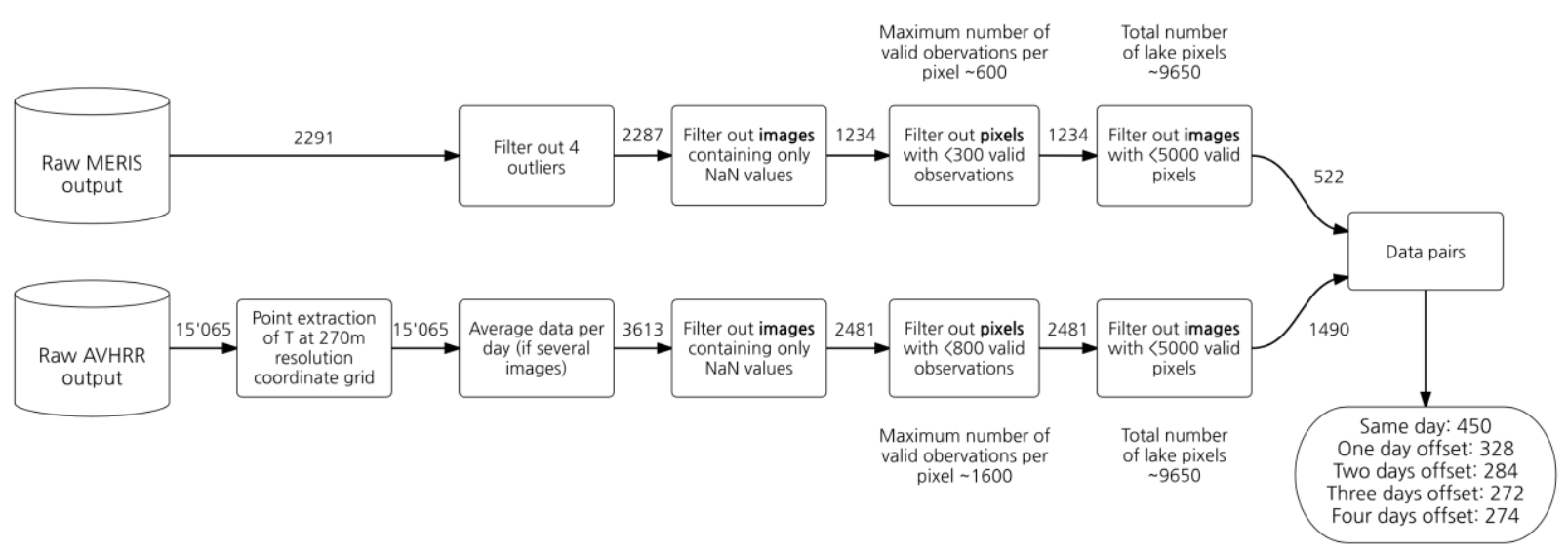

250 Figure 5. Workflow for the post-processing of the remote sensing images (CHL above; LSWT 251 below) and the setup of the CHL-LSWT pairs of the images. well as pairs with various temporal offsets (the LSWT image up to four days prior to the CHL 


\subsubsection{Moran's I analysis}

The analytic comparison of LSWT and CHL concentrations from the same day is

261 262

263 264

265 266 267 268

271 272 273 274 275 278

276 including the 4 to 440 NN pixels (Table 1). The variation in the number of NN allows comparing 277 the spatial extent of the correlation, with areas varying from $0.29 \mathrm{~km}^{2}(\mathrm{NN}=4)$ to $32.08 \mathrm{~km}^{2}$ approached by means of a spatial clustering analysis. The univariate Moran's I (Moran, 1950) is an indicator of the degree of spatial autocorrelation of a given parameter. High Moran's I values refer to "the presence, absence, or degree of a certain characteristic affecting the presence, absence, or degree of the same characteristic in neighbouring units" (Congalton, 1991). In this study, we use the bivariate Moran's I which allows to use two variables (CHL and LSWT). In that case, the value of the first parameter, $\mathrm{CHL}$, in pixel $i$ is compared to the value of the second parameter, LSWT, in all its pixels $j$.

$$
I=\frac{N}{\sum_{i} \sum_{j} w_{i j}} \frac{\sum_{i} \sum_{j} w_{i j}\left(C H L_{i}-\overline{C H L}\right)\left(L S W T_{j}-\overline{L S W T}\right)}{\sqrt{\sum_{i}\left(L S W T_{i}-\overline{L S W T}\right)^{2}} \sqrt{\sum_{i}\left(C H L_{i}-\overline{C H L}\right)^{2}}}
$$

Whereas $N$ is the total number of pixels in each image, $w_{i j}$ is the weight given to each individual pixel pair. All pixels that are taken into account as neighbours have the same weight (a fraction of 1) and all other pixels have a weight of 0 . The sum of all weights is $\sum_{i} \sum_{j} w_{i j}=1 . \overline{C H L}$ and

$74 \overline{L S W T}$ are the respective arithmetic means of all values in the considered image pair. The computation was carried out for all product pairs, and repeated for eight neighbourhood ranges $78(\mathrm{NN}=440)$. 
279 Table 1: Number of nearest neighbours (NN) used in the weight file of the computation of 280 Moran's I and their corresponding lake surface area.

\begin{tabular}{l|l} 
Number of NN & $\begin{array}{l}\text { Surface covered by } \\
\text { the included pixels } \\
\left(\mathrm{km}^{2}\right)\end{array}$ \\
\hline 0 & 0.00 \\
\hline 4 & 0.29 \\
\hline 8 & 0.58 \\
\hline 24 & 1.75 \\
\hline 48 & 3.50 \\
\hline 80 & 5.83 \\
\hline 120 & 8.75 \\
\hline 224 & 16.33 \\
\hline 440 & 32.08
\end{tabular}

281

282 Values of $I$ between 0 and +1 indicate a positive spatial correlation with respect to the 283 neighbourhood range. Practically, higher CHL value pixels are surrounded by higher LSWT 284 value pixels for a given image pair. Negative $I$, between -1 and 0 , indicate a negative spatial 285 correlation, where neighbouring values tend to have opposite variations. Practically, pixels with 286 higher CHL values are surrounded by pixels of lower LSWT values and vice versa. Values close 287 to zero indicate that there is no significant structure. Significance of the spatial correlation is 288 tested by randomization (using 999 permutations), comparing the estimation of the expectation 289 value of Moran's I for random spatial distributions with the obtained result. Only results with $\mathrm{p}<$ 2900.05 are considered. All calculations were performed using the Python package PySAL (function 291 pysal.esda.moran.Moran_BV; Rey, 2015). 


\section{Results}

\subsection{CHL and LSWT correlations}

The spatial correlation between image pairs of CHL and LSWT varied from a Moran's I of 0.8 to +0.7 , e.g., CHL peaks correlated with either colder or warmer surrounding LSWT. Over the 10-year period, eight out of the top ten positive events occurred in spring (Table 2). Similarly, nine out of the top ten (Table 2) negative spatial correlations occurred in summer or in the beginning of autumn. This correlation analysis suggests a seasonal variability in CHL dynamics with mostly positive correlation with LSWT in spring and negative in summer and 300 autumn.

301 302

303

Table 2: Dates of the ten highest positive (left) and ten lowest negative (right) Moran's I for data pairs of CHL and LSWT.

\begin{tabular}{l|l|l|l} 
Date & Moran's $I$ & Date & Moran's $I$ \\
\hline 06 April 2010 & 0.71 & 09 September 2011 & -0.81 \\
\hline 20 October 2007 & 0.68 & 10 September 2009 & -0.80 \\
\hline 05 April 2010 & 0.68 & 13 October 2011 & -0.80 \\
\hline 11 April 2010 & 0.66 & 26 April 2011 & -0.79 \\
\hline 22 March 2011 & 0.55 & 23 July 2008 & -0.70 \\
\hline 25 April 2007 & 0.52 & 31 July 2007 & -0.65 \\
\hline 21 March 2011 & 0.52 & 18 August 2007 & -0.59 \\
\hline 24 April 2009 & 0.50 & 01 June 2005 & -0.58 \\
\hline 10 September 2011 & 0.49 & 27 July 2007 & -0.57 \\
\hline 29 May 2010 & 0.49 & 01 September 2010 & -0.55
\end{tabular}

\subsubsection{Seasonal trend}

The monthly ratio $(\mathrm{R})$ between the number of positive and negative values for Moran's $I$ of the image pairs provides a straightforward synthesis of the temporal dynamics in the correlation between CHL and LSWT (Figure 6). A $R$ ratio larger than (respectively lower than) 1 
308 indicates monthly dynamics dominated by positive (respectively negative) correlations between

309 CHL and LSWT. As expected, based on the dynamics of stratification and nutrient limitation, all

310 data show $\mathrm{R}>1$ in March and April, and $\mathrm{R}<1$ later in the year.
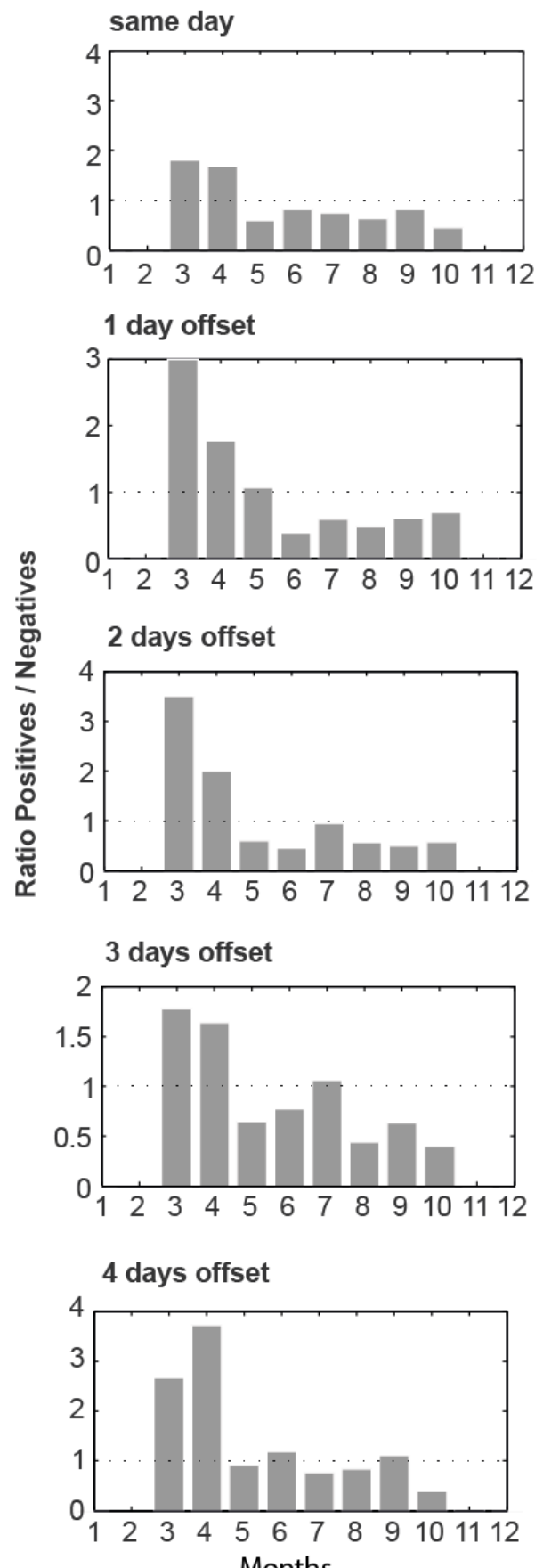

312 Figure 6. Ratio of the number of positive to negative Moran's I results (4 NN) per month for 313 different temporal offsets. The dotted line (ratio =1) indicates equal positive / negative numbers. 


\section{3.1.2 Correlation for different temporal offsets}

315 Deriving Moran's I for data pairs of different temporal offsets allows for including some

316 of the temporal correlation range and hence for the inference of causative processes. Correlations

317 at no or at short time offsets are expected to represent vertical or horizontal advection of water

318 with CHL being temporarily relocated close to the surface and becoming accessible by remote

319 sensing techniques. Correlations at a larger temporal offset are likely to represent phytoplankton

320 growth resulting from lateral or vertical advection of any limiting compounds like nutrients. The

321 intensity value of $R$ (Figure 6) is most pronounced for data pairs with one and two days offset.

322 After three days, the ratios in spring (March and April) remain above 1, while the trend in the

323 ratio approaches 1 from May to September for three or four days of temporal offset.

\section{3.1.3 Spatial correlation for different lateral extents}

Deriving Moran's I with different lateral extents (different numbers of NN) allows examining the horizontal size of the observed pattern. The sign of Moran's I does not change

327 when increasing the number of NN (Figure 7) and positive results for 4 low NN remain positive

328 for large $440 \mathrm{NN}$. The values, however, decline slightly when taking larger surface extents into

329 account, indicating a decrease of correlation when moving further away from the point of

330 comparison (central CHL pixel). Correlation remains typically high until $\mathrm{NN} \approx 80$ corresponding

331 to an area of $5.9 \mathrm{~km}^{2}$. When analysing this correlation for different CHL concentration in the

332 lake (Appendix B), we observe that correlation extends over larger areas when CHL is high, but

333 smaller extent for weak CHL. 

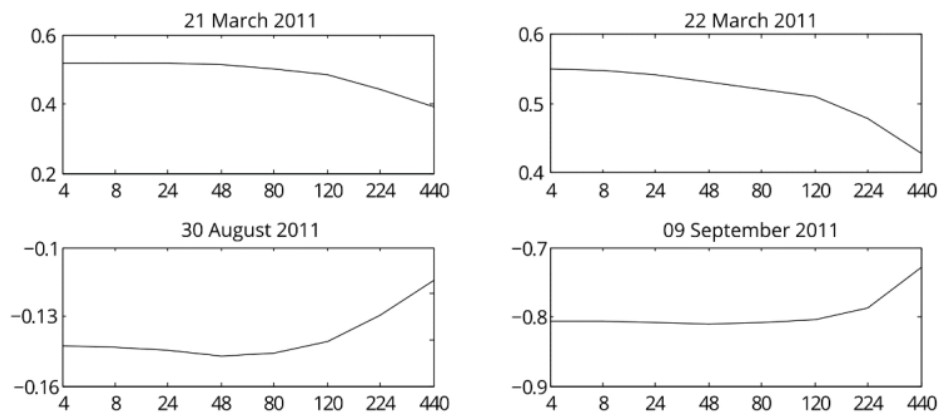

09 September 2011
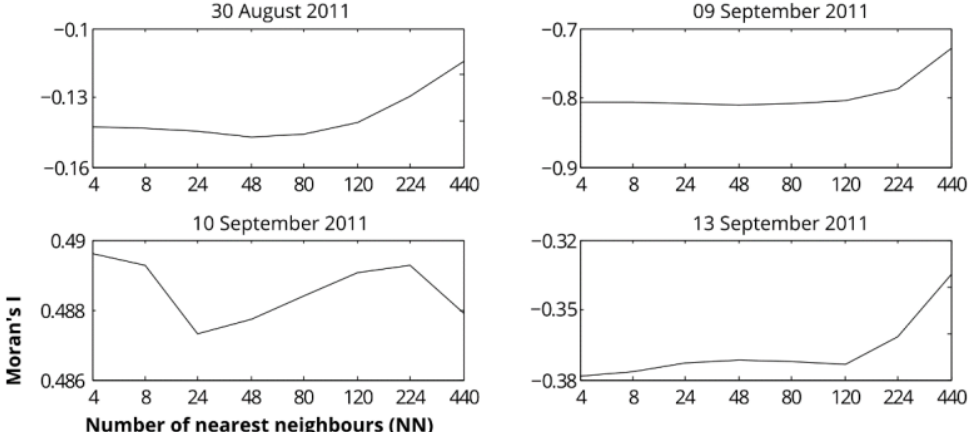

Figure 7. Moran's I for 4 to 440 NN. Dates correspond to those of Figures 9 and 10.

In conclusion, the statistical analysis suggests: (i) a seasonal variability in the correlation

between CHL and LSWT, (ii) the strongest correlation with an offset of 1 or 2 days between

338 CHL and LSWT, unfortunately preventing a statistical distinction between CHL growth and

339 transport, and (iii) lateral horizontal correlation scales that suggest hydrodynamic drivers playing

340 a key role for the often horizontally limited phytoplankton abundance. We therefore investigate

341 the influence of the wind as the main external force driving lake dynamics and potentially

342 responsible for the spatial variability.

\section{3.2 Influence of the wind on lake dynamics}

The effect of the wind on the correlation between LSWT and CHL was tested by comparing the statistical Moran's I correlation to a non-dimensional wind ratio. This wind ratio

346 scale was constructed as the ratio between the three-days average wind intensity prior to the

347 LSWT acquisition and the three-days average wind recorded at the MeteoSwiss station in Pully

348 over the entire ten years considered. The three-days window length was chosen to be close to the

349 longitudinal basin-scale internal wave period for Lake Geneva (Bouffard and Lemmin, 2013). 
350 Correlation data were split into two subsets, for spring and summer correlation, respectively, as

351

352

353

354

355

356

357

358

359

360

361

362

363

364

365

366 defined above.

Spring correlations do not show any significant relationship of Moran's I correlation with wind (Figure 8). We observed highly correlated images following both high and low wind intensity. The summer cases are more instructive. As shown in Figure 8, highly (negative) correlated images followed above-average wind strengths in summer.

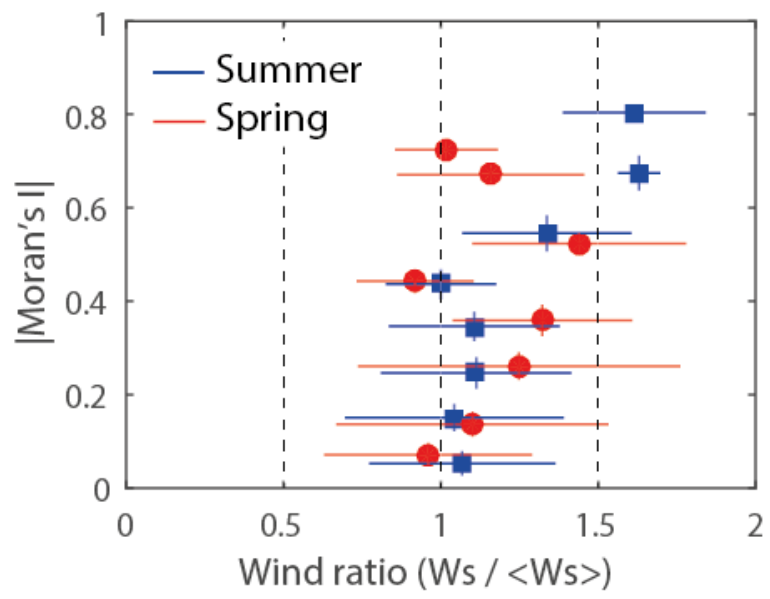

Figure 8. Bin averaged absolute Moran's I as a function of the wind ratio. Wind ratio is defined as the ratio between the wind averaged over the three-days prior to the satellite image to the wind averaged over ten years. High Moran's I in summer are associated with high winds.

A mechanistic evaluation of the correlation between LSWT and CHL requires more information on the spatial and temporal dynamics of lake temperature and CHL. Wind analysis already suggested at least three cases depending on the wind intensity and the period of the year (case 1: high wind in spring; case 2: high wind in summer; case 3: low wind). We investigated the first two cases by means of in-situ measurements, satellite data, and hydrodynamic modelling. The latter case 3 is not further reported in this study because forcing becomes more complex at low wind speeds. 


\section{3.2.1 Case 1. High wind prior to high image pair correlation in spring}

368 The period of 21/22 March 2011 corresponds to this case. Images have a high positive

369 Moran's I correlation of 0.52 and 0.55 (Table 2) and are following a strong north-east wind event

370 (Figure 9a) on 19 and 20 March. Both LSWT from satellites and model data show the same

371 pattern with colder surface water in the western part of the lake center and warmer water on both

372 western and eastern end (Figures 9cd). This observation is in good agreement with the

373 thermocline being close to the surface at the lake center and being strongly lowered on both ends

374 (Figure 9f). This downwelling structure on both ends of the basin is explained by the spatially

375 heterogeneous wind structure (Figure 9e). The strong north-east wind is likely perturbed by the

376 local topography of the surroundings of the lake, with the steep Alpine mountain slopes south of

377 the lake. As a consequence, part of the northern wind field on the eastern part of the lake is

378 deviated towards the east (Figure 9e) leading to a second smaller unexpected downwelling zone

379 in this area. This example suggests that in spring, downwelling areas can lead to high CHL near

380 the lake surface (Figure 9b). 
a)

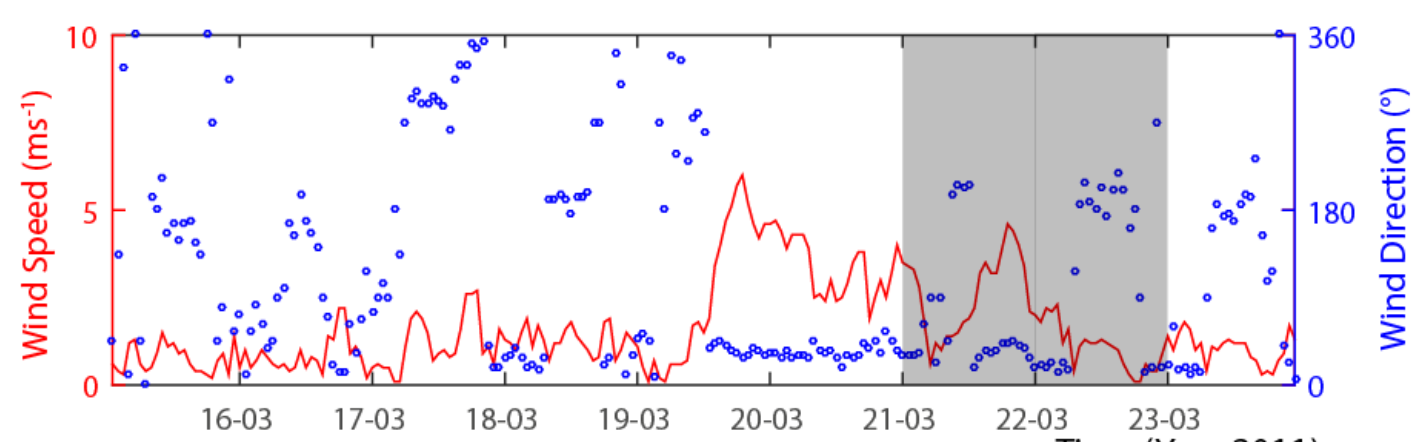

b)

21-03-2011

Time (Year 2011)

22-03-2011
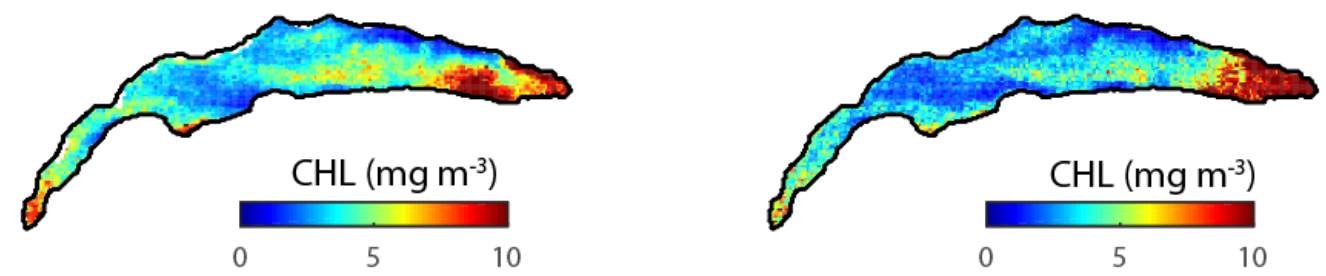

c)

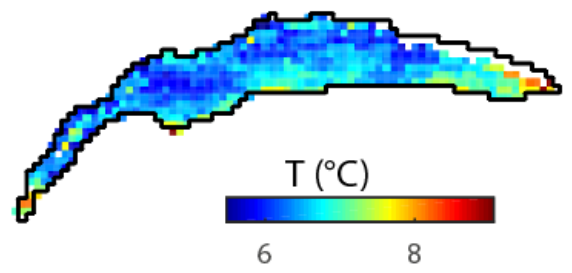

d)

e)
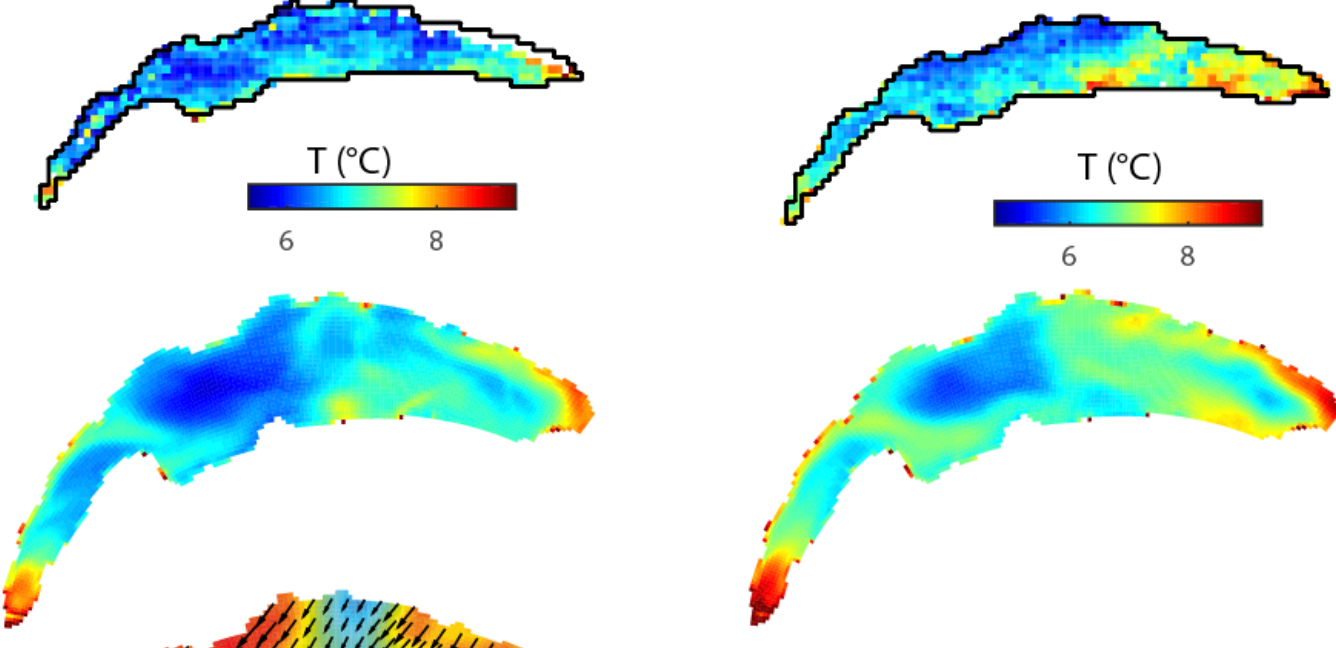

Wind Speed $\left(\mathrm{m} \mathrm{s}^{-1}\right)$
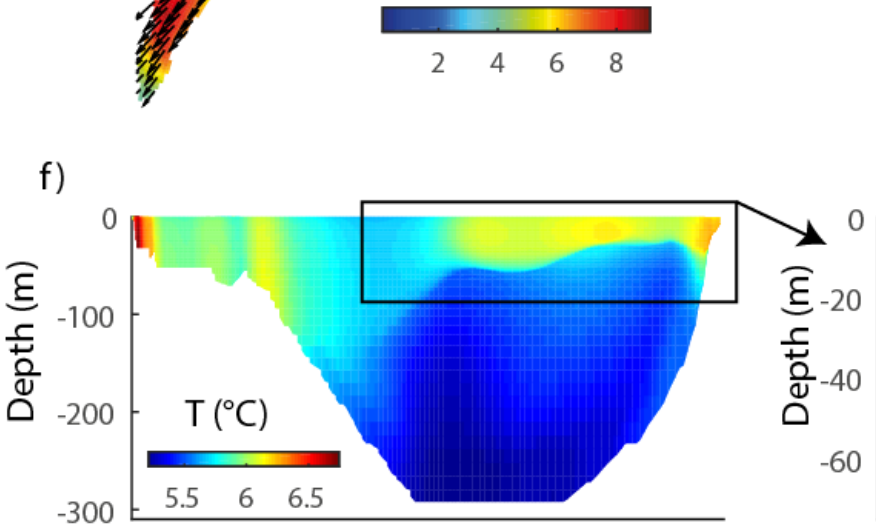
Figure 9. a) Wind magnitude and direction. Shaded area represent the investigated day with LSWT and CHL satellite data. b) CHL satellite image for 21 March 2011 (left) and 22 March 2011 (right). c) LSWT satellite image for 21 March 2011 (left) and 22 March 2011 (right). d) LSWT modelled for 21 March 2011 (left) and 22 March 2011 (right). e) Wind magnitude (colour-coded) and direction (arrows) for 20 March 2011. Data from COSMO-2 meteorological model; f) Longitudinal transect of temperature over the water column for day 20 March 2011 extracted from the hydrodynamic model.

\subsubsection{Case 2. High wind prior to high image pair correlation in summer}

The period of September 2011 corresponds to this case. The AVHRR and MERIS images from 9 September have a large negative Moran's I correlation of -0.81 (Table 2; Figures 10bcfg) and is following strong winds from the south-west over the previous three days.). The previous image pair from 30 August shows an almost homogenous horizontal CHL distribution while the three following image pairs (9, 10 and 13 September, Figures 10bcfg) indicate higher CHL in the Petit Lac of Lake Geneva.

The qualitative agreement between AVHRR data and the hydrodynamic model is excellent, but - comparing the two - we noticed small horizontal offsets ( $250 \mathrm{~m})$ between warm and cold areas (Figures 10cdgh). However, compared to the lake size (length: $74 \mathrm{~km}$ ), this is small enough to allow a comparison between the satellite and model data. Time series of surface temperature data in Buchillon (Figure 2) show a very good agreement between satellite, model and in-situ data (Figure 10k).

On 9 / 10 September 2011, the lake surface is significantly colder in the western part (Petit Lac) and on the north-western part of the Grand Lac (Figures 10cdgh). The thermocline excursion extracted from the 3D model suggests that these areas correspond to strong upwelling zones where the thermocline almost reaches the surface on the 9 of September 2011 (Figure 10e). This upwelling is also clearly noticeable on a longitudinal transect (Figure 10j). This 
408 second example suggests that in summer, strong wind-induced upwelling can lead to high CHL 409 near the lake surface (Figures $10 \mathrm{bf}$ ). 
a)

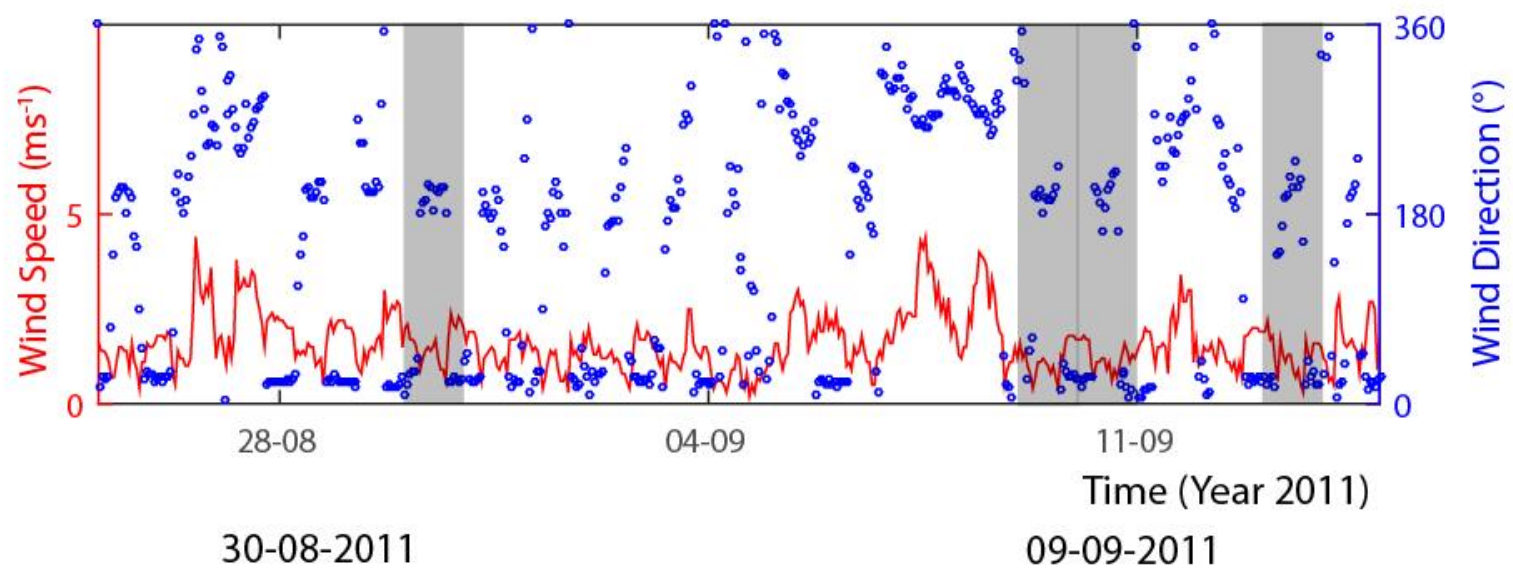

b)
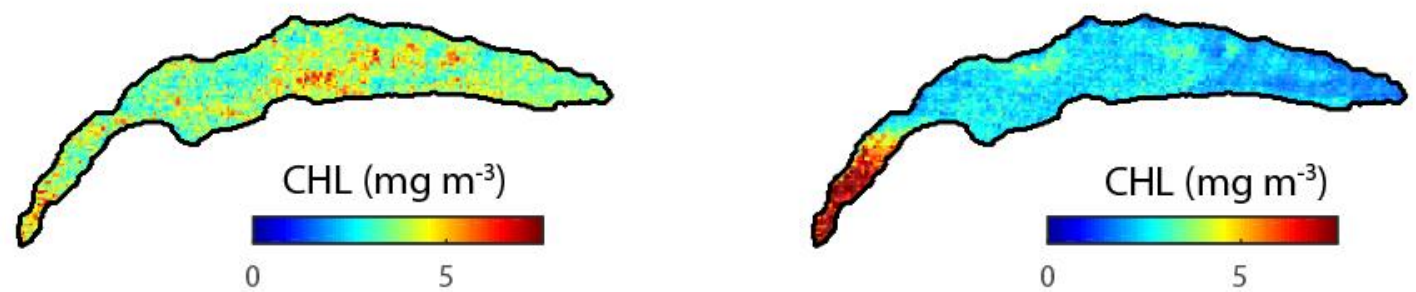

c)
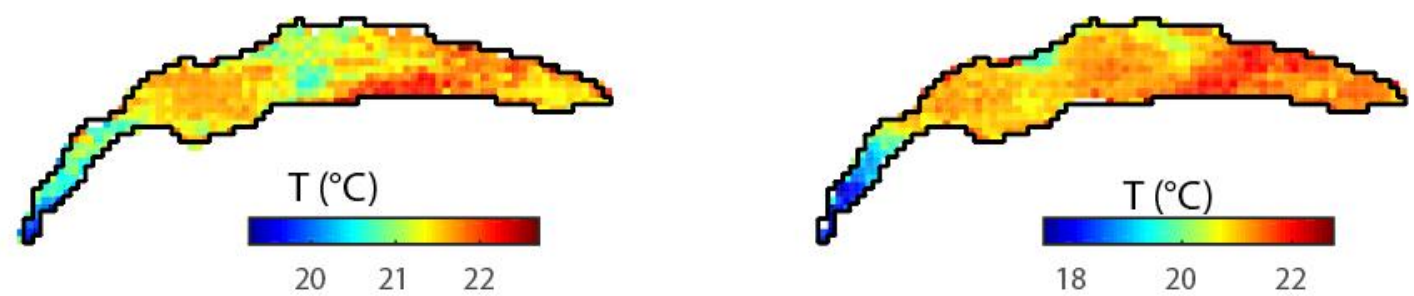

d)
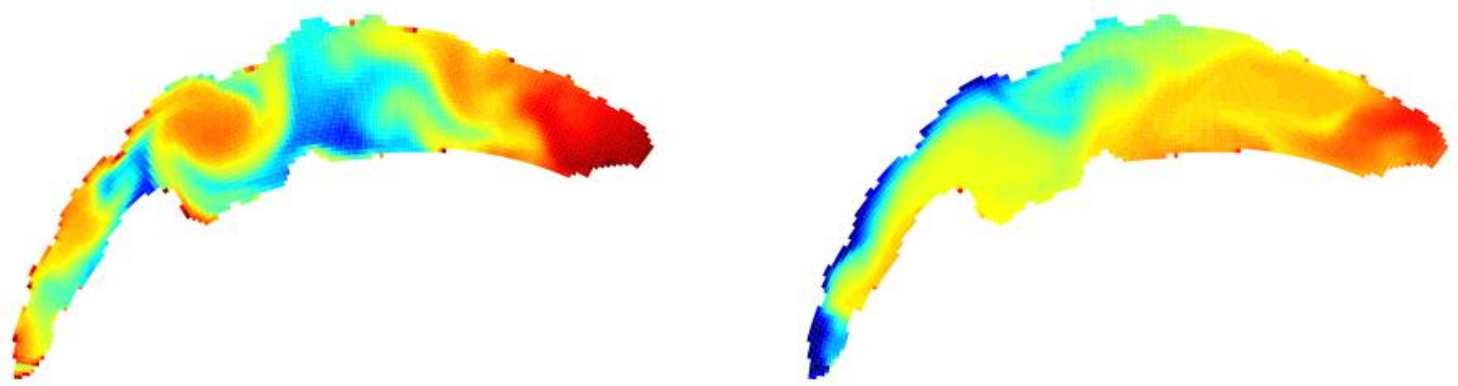

e)
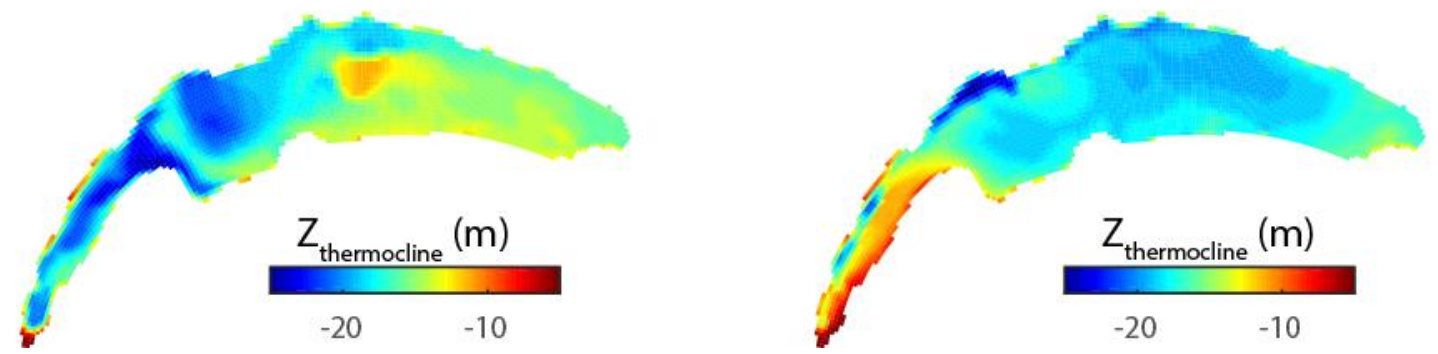
f)

$$
\text { 10-09-2011 }
$$

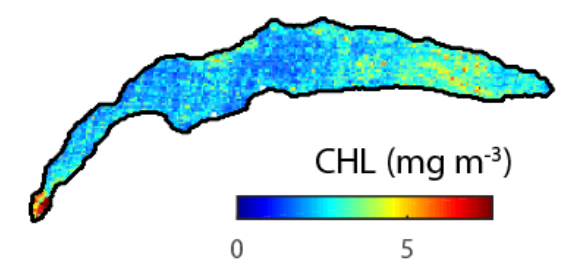

g)

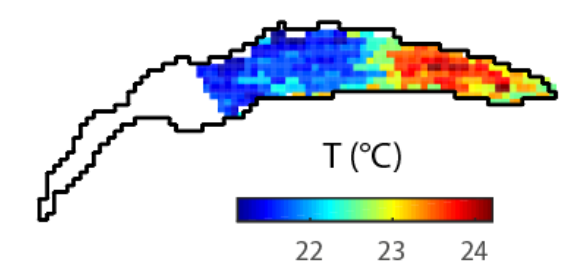

h)

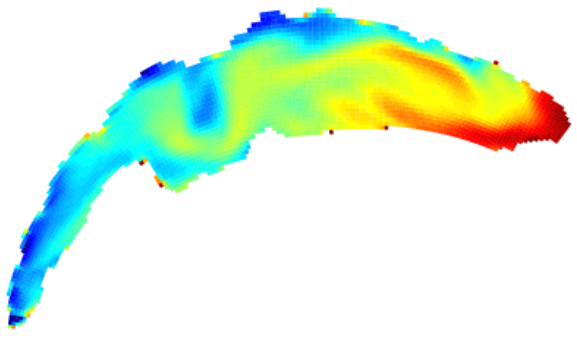

i)

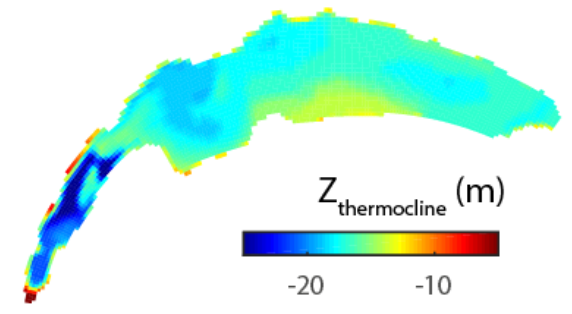

j)
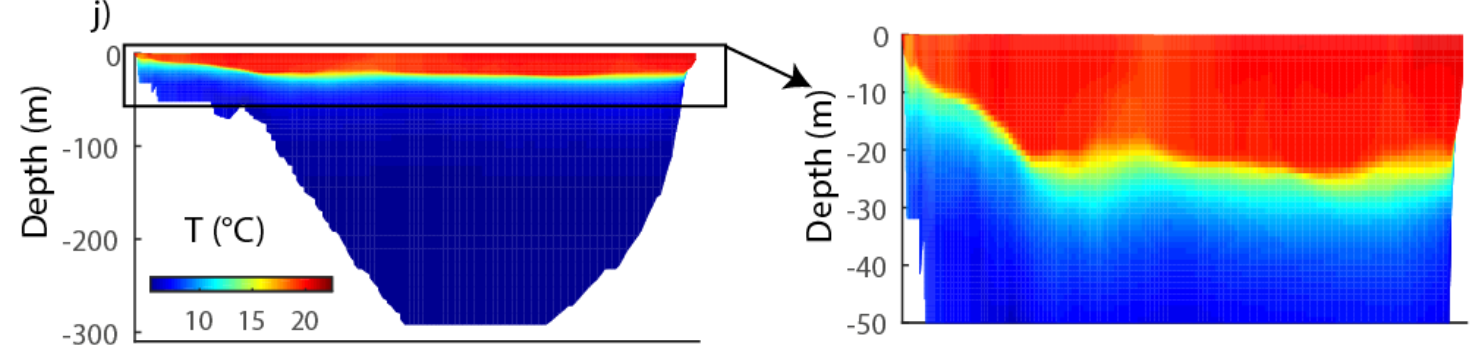

k)
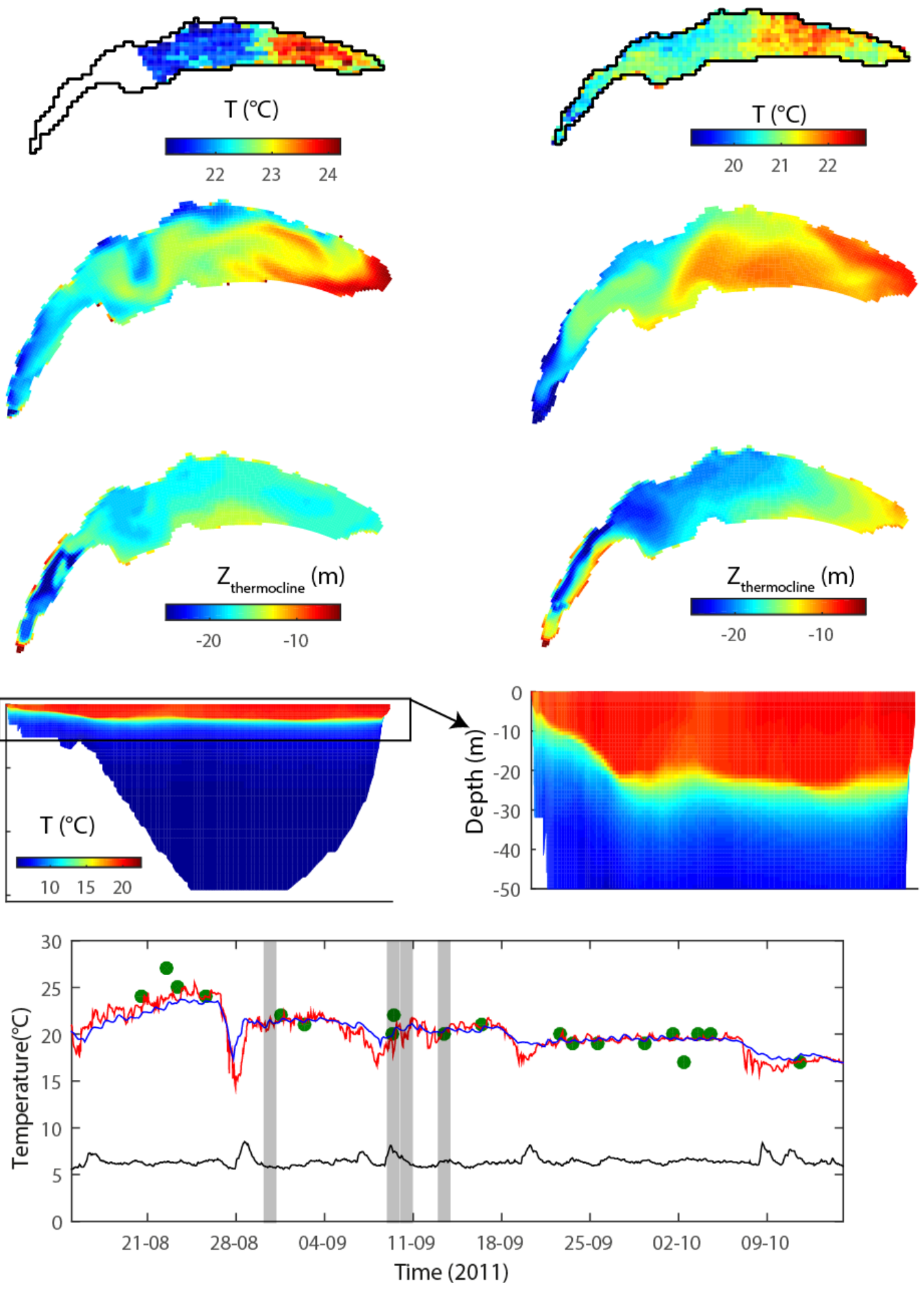
412 Figure 10. a) Wind magnitude and direction. Shaded area represent the investigated day with 413 LSWT and CHL satellite data. b) CHL satellite image for 30 August 2011 (left) and 09

414 September 2011 (right). c) LSWT satellite image for 30 August 2011 (left) and 09 September

4152011 (right). d) LSWT model data for 30 August 2011 (left) and 09 September 2011 (right). e)

416 modelled thermocline depth for 30 August 2011 (left) and 09 September 2011 (right). j)

417 Longitudinal transect of temperature over the water column for day 08-09-2011.f) - i) same as

418 b) - e) but for the days 10 September 2011 (left) and 13 September 2011. k) Time series of in-situ

419 (red line, $1 \mathrm{~m}$ depth; black line, $36 \mathrm{~m}$ depth), modelled temperature (blue line, $1 \mathrm{~m}$ depth), and

420 remotely sensed LSWT (green dots).

\section{Discussion}

\subsection{Spring correlation}

The analysis of CHL and LSWT image pairs has pointed out different correlations depending

on the season. Spring phytoplankton growth appears here temperature-limited. Warmer zones of the lake show enhanced CHL and the correlation between the two parameters is positive for all temporal offsets. Most of the top positive Moran's I are observed during spring. In the case of Lake Geneva, the absolute level of LSWT in springtime may be less critical for algal growth than the surface layer stratification and implicitly the water column stability. Depending on the phytoplankton species, a stratified water column is needed to allow these organisms to stay in the photic layer. The onset and strength of stratification is not uniform over the whole lake, warmer zones in spring indicate areas where the surface layer is already more stable. Taylor and Ferrari (2011) found that a bloom developed due to the start of net warming, weakening turbulent mixing, and a subsequent increase in the residence time of phytoplankton cells within the euphotic layer. Ferreira et al. (2015) support these findings, stating that among several active

436 mixing models for North Atlantic there was a bias towards mechanisms involving heat flux. The 437 detailed example of March 2011 shows two downwelling regions associated with high CHL. 
Downwelling regions and associated warmer surface water with pronounced stratification are therefore found to be hot spots for spring algae growth in Lake Geneva.

\subsection{Summer correlation}

From the bi-monthly in-situ measurements at location SHL2 (Figure 2) it can be observed that the CHL maxima in Lake Geneva are at $\sim 3$ to $5 \mathrm{~m}$ depth in March and April, and gradually move to $\sim 8$ to $10 \mathrm{~m}$ depth by late summer. This phenomenon is linked to the deepening of the stratification and to the vertical structure of depleted nutrients in the photic zone (Anneville et al., 2002). From a uniformly distributed phosphate concentration after winter convective mixing (Figure 4), this component gets quickly depleted at the surface as biological activity sets in. From a temperature-limited phytoplankton growth in spring, the lake turns to a nutrient-limited growth in summer. By temperature-limited phytoplankton growth, we therefore include the contribution from the absolute temperature as well as the light limitation related to the build-up of thermal structure. The spring stratification and modifications of the turbulence level can maintain certain phytoplankton for longer in the photic zone and thereby reduce the light limitation which remains a strong constraint in winter and spring. The combination of remote sensing observations with hydrodynamic and eventually biogeochemical models provide an efficient tool to investigate the mechanisms responsible for spring blooms in lakes.

Such a nutrient-limited structure is apparently consistent with observations of enhanced $\mathrm{CHL}$ in colder upwelling zones during the summer months. The first hypothesis is that upwelled nutrient-rich, colder water from deeper layers is responsible for phytoplankton growth in the photic layer during that season. The 1-2 days shift for the highly negative correlation between CHL and LSWT pleads also for a rapid growth of algae following nutrient uptake by upwelling events. However, the summer deep CHL maximum in Lake Geneva is often at depths that 
contribute only a minor part to the water-leaving radiance signal (Kiefer et al., 2015). Therefore, it may remain unnoticed by remote sensing observation until an upwelling mixes it with colder water from below and conveys it towards the surface, where it becomes measurable for remote optical sensors. Such a second hypothesis of near-surface pseudo algae blooms were previously observed in the Experimental Lakes (Fee, 1976), where not only nutrients, but also deep phytoplankton were brought to the surface by upwelling and mixing events.

As the satellite data in the visible range are still relatively sparsely, though, we cannot quantitatively assess the role of upwellings as supplier of deep nutrients or phytoplankton to the surface. Typically, it takes one to three days for nutrients to be incorporated into biomass by growth (Reynolds and Irish, 1997), and this time remains shorter than the typical revisiting time of MERIS. An immediate increase in CHL after upwelling would therefore indicate a redistribution of phytoplankton along the water column, rather than a redistribution of nutrients and a consequent growth of phytoplankton in the epilimnion. We finally try to distinguish between upward transport of already existing deep CHL maximum or nutrients into the surface layer by investigating the remote sensing data with respect to the basin-scale internal wave oscillation following the first wind-induced upwelling-downwelling inferred from high temporal resolution 3D hydrodynamic modelling.

\subsection{Role of basin-scale internal waves}

An analysis of the 3D hydrodynamic model for the period of September - October 2011 indicates that the lake dynamics is driven by a characteristic basin-scale internal wave. We show, based on basin-scale internal wave isotherm vertical dislocations (Figure 11), that the investigated LSWT - CHL correlation in September 2011 results from an upward transport of the deep CHL maximum. The two consecutive CHL images on $9^{\text {th }}$ and $10^{\text {th }}$ September 2011 are 
484 particularly meaningful. After the wind-induced upwelling on $7^{\text {th }}$ and $8^{\text {th }}$ of September, we 485 observe a negative correlation with cold surface temperature and elevated CHL in Petit Lac on 486 the $9^{\text {th }}$ of September. However, the satellite image indicates almost no near surface CHL on the 487 next day ( $10^{\text {th }}$ of September) except at the very western end. On this day, the Petit Lac thermal 488 structure corresponds to a downwelling situation and we observe a weak upwelling area at the 489 southern shore of the Grand Lac. This upwelling/downwelling feature travelling up to $2 / 3$ of the 490 longitudinal distance of Lake Geneva with an anticlockwise circulation is the typical signature of 491 an internal Kelvin wave with a period of 3.5 days for late summer (Bouffard and Lemmin, 2013).

492 Kelvin waves are common features as can be seen with the two consecutive peaks observed in 493 the temperature time series at $36 \mathrm{~m}$ depth (Buchillon, Figure 10). The anticlockwise Kelvin wave 494 motion of the investigated period is shown in Figure 11 from the detrended temperature 495 oscillation at $20 \mathrm{~m}$ depth (thermocline). We note a second passage of Kelvin waves in the Petit 496 Lac on the $12^{\text {th }}$ and $13^{\text {th }}$ of September associated with downwelling. This second passage is 497 shown by the MERIS data as an increase in CHL on the $12^{\text {th }}$ (not shown) and the $13^{\text {th }}$ September 4982011 (Figure 10). The following MERIS images in September and October 2011 do not show 499 any near-surface CHL enhancement (not shown). We conclude from this coupled 3D modelling 500 and remote sensing study that the summer negative correlation in LSWT and CHL can be 501 associated with wind-induced basin-scale internal waves (e.g. Kelvin waves) pushing the 502 thermocline upward, thereby transporting temporarily the deep CHL maximum close to the 503 surface. 


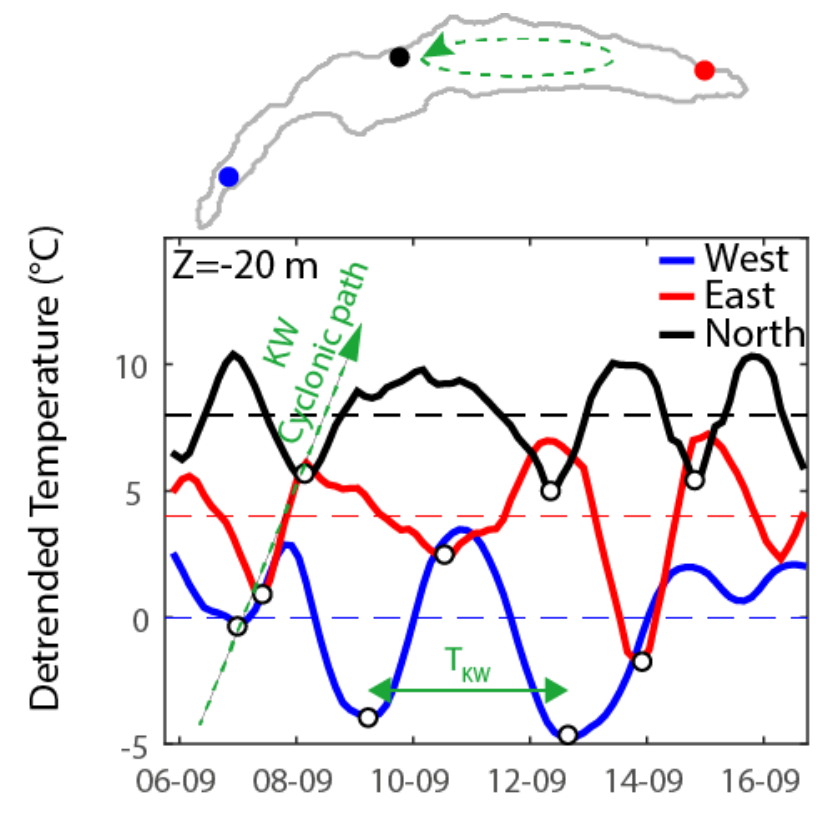

Time (dd-mm 2011)

505 Figure 11. Detrended modelled temperature time series at $20 \mathrm{~m}$ depth on three control points 506 across the lake. Data have been offset vertically by $5^{\circ} \mathrm{C}$ (East control point) and $10{ }^{\circ} \mathrm{C}$ (North 507 control point). The $\sim 3.5$-day oscillation corresponds to a Kelvin wave with cyclonic propagation 508 along the shore.

\section{Conclusion} Remotely sensed surface temperature (LSWT) and chlorophyll images (CHL) of a large

512 lake show sequences of intriguing positive and negative correlations (Figure 1). We used in-situ 513 data, remote sensing data, and three-dimensional (3D) hydrodynamic modelling to investigate

514 their relationship. Two types of correlations between LSWT and CHL were observed with

515 mostly positive correlation in spring and negative correlation in summer and autumn. In spring,

516 we observed elevated correlation both under windy and calm conditions. In summer and autumn,

517 strong negative correlations were following an episode of increased wind intensity in the days

518 preceding the image pair. Spring positive correlation indicates that CHL growth is temperature-

519 related. We identified downwelling zones associated with higher CHL than in the rest of the 
520 lake. The increase of CHL resulted from warmer surface temperature and/or stronger

521 stratification in the downwelling zone. Summer and autumn negative correlation were associated

522 with upwelling zones and colder surface water. Two driving mechanisms were investigated as

523 cause of increased CHL in these regions: (i) upwelling bringing nutrients to the photic zone, and

524 (ii) upwelling transport and mixing of deep CHL maxima of the photic zone to the lake surface.

525 The analysis of remotely sensed CHL images based on basin-scale internal wave dynamics

526 suggests that in the deep large Lake Geneva, negative summer and autumn correlations result

527 from the deep CHL maxima being upwelled close to the surface and becoming accessible to

528 satellite observations.

529 From a remote sensing point of view, special care should be taken on the data

530 interpretation of summer and autumn algae blooms in deep large lakes. This study suggests that

531 some of the blooms are in fact the signature of deep CHL maxima temporarily moved up near

532 the surface by large internal wave motions. Recent satellites with shorter revisiting times and

533 smaller pixel resolutions, such as Sentinel-2 and Sentinel-3, will provide new remotely sensed

534 information to analyse the dynamics of lake ecosystems at unprecedented temporal and spatial

535 scales

536 The coupling between in-situ data, remote sensing observations, and hydrodynamic

537 modelling was shown to provide insightful results, each information source being able to

538 compensate for the weakness of other data sources. Further studies should focus on a deeper

539 integration of the information sources. 
541 We are thankful to the Swiss Federal Office of Meteorology and Climatology, MeteoSwiss, for

542

543

544

545

546

547

548

549

providing us with spatiotemporal meteorological data. We also thank the Eco-Informatics ORE INRA Team at the French National Institute for Agricultural Research (SOERE OLA-IS, INRA Thonon-les-Bains) for collecting water temperature profiles at SHL2 station, and SECOE Direction Générale de l'Eau du Canton de Genève $(\mathrm{CH})$ for water temperature measurements at GE3 station. We thank Michael Riffler for the processed LSWT products based on AVHRR data. We thank Ulrich Lemmin and Claude Perrinjaquet for the data at Buchillon mast. We finally thank Karsten Rinke and two other anonymous reviewers for their valuable comments and constructive suggestions on the manuscript.

\section{References}

Anneville, O., Souissi, S., Ibanez, F., Ginot, V., Druart, J.C., Angeli, N., 2002. Temporal mapping of phytoplankton assemblages in Lake Geneva: annual and interannual changes in their patterns of succession. Limnol. Oceanogr. 47, 1355-1366.

Barbiero, R.P., Tuchman, M.L., 2004. The deep chlorophyll maximum in Lake Superior. J. Gt. Lakes Res. 30, 256-268.

Behrenfeld, M.J., Boss, E.S., 2014. Resurrecting the Ecological Underpinnings of Ocean Plankton Blooms. Annu. Rev. Mar. Sci. 6, 167-194. https://doi.org/10.1146/annurevmarine-052913-021325

Berger, S.A., Diehl, S., Stibor, H., Trommer, G., Ruhenstroth, M., 2010. Water temperature and stratification depth independently shift cardinal events during plankton spring succession. Glob. Change Biol. 16, 1954-1965.

Bouffard, D., Lemmin, U., 2013. Kelvin waves in Lake Geneva. J. Gt. Lakes Res. 39, 637-645.

Bouffard, D., Perga, M.-E., 2016. Are flood-driven turbidity currents hot spots for priming effect in lakes? Biogeosciences 13, 3573-3584.

Bourg, L., Etanchaud, F., 2007. The AMORGOS MERIS CFI (Accurate MERIS Ortho-Rectified Geo-location Operational Software) software user manual \& interface control document. ACRI-ST Sophia-Antipolis Fr. Tech Rep 3.

Bouvet, M., Ramoino, F., 2010. Equalization of MERIS L1B products from the 2nd reprocessing (No. ESA TN TEC-EEP/2009.521). ESA.

Congalton, R.G., 1991. A review of assessing the accuracy of classifications of remotely sensed data. Remote Sens. Environ. 37, 35-46.

Curtarelli, M.P., Ogashawara, I., Alcântara, E.H., Stech, J.L., 2015. Coupling remote sensing bio-optical and three-dimensional hydrodynamic modeling to study the phytoplankton dynamics in a tropical hydroelectric reservoir. Remote Sens. Environ. 157, 185-198. https://doi.org/10.1016/j.rse.2014.06.013 
Dokulil, M.T., Teubner, K., 2012. Deep living Planktothrix rubescens modulated by environmental constraints and climate forcing. Hydrobiologia 698, 29-46.

Falkowski, P.G., Barber, R.T., Smetacek, V., 1998. Biogeochemical controls and feedbacks on ocean primary production. Science $281,200-206$.

Fee, E.J., 1976. The vertical and seasonal distribution of chlorophyll in lakes of the Experimental Lakes Area, northwestern Ontario: Implications for primary production estimates. Limnol. Oceanogr. 21, 767-783.

Ferreira, A.S., Hátún, H., Counillon, F., Payne, M., Visser, A., 2015. Synoptic-scale analysis of mechanisms driving surface chlorophyll dynamics in the North Atlantic. Biogeosciences 12, 3641-3653.

Fomferra, N., Böttcher, M., Zühlke, M., Brockmann, C., Kwiatkowska, E., 2012. Calvalus: Fullmission EO cal/val, processing and exploitation services, in: 2012 IEEE International Geoscience and Remote Sensing Symposium. Presented at the 2012 IEEE International Geoscience and Remote Sensing Symposium, pp. 5278-5281. https://doi.org/10.1109/IGARSS.2012.6352418

Gaudard, A., Schwefel, R., Vinnå, L.R., Schmid, M., Wüest, A., Bouffard, D., 2017. Optimizing the parameterization of deep mixing and internal seiches in one-dimensional hydrodynamic models: a case study with Simstrat v1.3. Geosci Model Dev 10, 34113423. https://doi.org/10.5194/gmd-10-3411-2017

Giardino, C., Pepe, M., Brivio, P.A., Ghezzi, P., Zilioli, E., 2001. Detecting chlorophyll, Secchi disk depth and surface temperature in a sub-alpine lake using Landsat imagery. Sci. Total Environ. 268, 19-29.

Goldman, J.C., Carpenter, E.J., 1974. A kinetic approach to the effect of temperature on algal growth. Limnol. Oceanogr. 19, 756-766.

Gruber, N., Lachkar, Z., Frenzel, H., Marchesiello, P., Münnich, M., McWilliams, J.C., Nagai, T., Plattner, G.-K., 2011. Eddy-induced reduction of biological production in eastern boundary upwelling systems. Nat. Geosci. 4, 787-792.

Hüsler, F., Fontana, F., Neuhaus, C., Riffler, M., Musial, J., Wunderle, S., 2011. AVHRR Archive and Processing Facility at the University of Bern: A comprehensive 1-km satellite data set for climate change studies. EARSeL EProceedings 10, 83-101.

Key, J.R., 2002. The Cloud and Surface Parameter Retrieval (CASPR) System for Polar AVHRR: User's Guide: Version 4.0. University of Wisconsin-Madison.

Kiefer, I., Odermatt, D., Anneville, O., Wüest, A., Bouffard, D., 2015. Application of remote sensing for the optimization of in-situ sampling for monitoring of phytoplankton abundance in a large lake. Sci. Total Environ. 527-528, 493-506. https://doi.org/10.1016/j.scitotenv.2015.05.011

Leboulanger, C., 2003. Dynamics of phytoplankton production and chlorophyll biomass in Lake Geneva, in: Rapport Commission Internationale Pour La Protection Des Eaux Du Léman, CIPEL, Campagne 2002.

Lemmin, U., D’Adamo, N., 1997. Summertime winds and direct cyclonic circulation: observations from Lake Geneva. Ann. Geophys. 14, 1207-1220.

MacIntyre, S., Jellison, R., 2001. Nutrient fluxes from upwelling and enhanced turbulence at the top of the pycnocline in Mono Lake, California. Hydrobiologia 466, 13-29.

Mackas, D.L., Denman, K.L., Abbott, M.R., 1985. Plankton patchiness: biology in the physical vernacular. Bull. Mar. Sci. 37, 652-674. 
Minnett, P.J., Smith, M., Ward, B., 2011. Measurements of the oceanic thermal skin effect. Deep Sea Res. Part II Top. Stud. Oceanogr. 58, 861-868.

Moran, P.A., 1950. Notes on continuous stochastic phenomena. Biometrika 37, 17-23.

Odermatt, D., Giardino, C., Heege, T., 2010. Chlorophyll retrieval with MERIS Case-2-Regional in perialpine lakes. Remote Sens. Environ. 114, 607-617.

Odermatt, D., Gitelson, A., Brando, V.E., Schaepman, M., 2012a. Review of constituent retrieval in optically deep and complex waters from satellite imagery. Remote Sens. Environ. 118, 116-126. https://doi.org/10.1016/j.rse.2011.11.013

Odermatt, D., Pomati, F., Pitarch, J., Carpenter, J., Kawka, M., Schaepman, M., Wüest, A., 2012b. MERIS observations of phytoplankton blooms in a stratified eutrophic lake. Remote Sens. Environ. 126, 232-239. https://doi.org/http://dx.doi.org/10.1016/j.rse.2012.08.031

Oesch, D.C., Jaquet, J.-M., Hauser, A., Wunderle, S., 2005. Lake surface water temperature retrieval using advanced very high resolution radiometer and Moderate Resolution Imaging Spectroradiometer data: Validation and feasibility study. J. Geophys. Res. 110. https://doi.org/10.1029/2004JC002857

Pomati, F., Jokela, J., Simona, M., Veronesi, M., Ibelings, B.W., 2011. An Automated Platform for Phytoplankton Ecology and Aquatic Ecosystem Monitoring. Environ. Sci. Technol. 45, 9658-9665. https://doi.org/10.1021/es201934n

Råman Vinnå, L., Wüest, A., Zappa, M., Fink, G., Bouffard, D., 2018. Tributaries affect the thermal response of lakes to climate change. Hydrol Earth Syst Sci 22, 31-51. https://doi.org/10.5194/hess-22-31-2018

Razmi, A.M., Barry, D.A., Bakhtyar, R., Le Dantec, N., Dastgheib, A., Lemmin, U., Wüest, A., 2013. Current variability in a wide and open lacustrine embayment in Lake Geneva (Switzerland). J. Gt. Lakes Res. 39, 455-465. https://doi.org/10.1016/j.jglr.2013.06.011

Razmi, A.M., Lemmin, U., Bouffard, D., Wüest, A., Uittenbogaard, R.E., Barry, D.A., 2017. Gyre formation in open and deep lacustrine embayments: the example of Lake Geneva, Switzerland. Environ. Fluid Mech. 17, 415-428. https://doi.org/10.1007/s10652-0169494-8

Reynolds, C.S., 2006. The ecology of phytoplankton. Cambridge University Press.

Riffler, M., Lieberherr, G., Wunderle, S., 2015. Lake surface water temperatures of European Alpine lakes (1989-2013) based on the Advanced Very High Resolution Radiometer (AVHRR) 1 km data set. Earth Syst. Sci. Data 7, 1-17. https://doi.org/10.5194/essd-7-12015

Rimet, F., Druart, J.-C., Anneville, O., 2009. Exploring the dynamics of plankton diatom communities in Lake Geneva using emergent self-organizing maps (1974-2007). Ecol. Inform. 4, 99-110.

Rinke, K., Huber, A.M.R., Kempke, S., Eder, M., Wolf, T., Probst, W.N., Rothhaupta, K.-O., 2009. Lake-wide distributions of temperature, phytoplankton, zooplankton, and fish in the pelagic zone of a large lake. Limnol. Oceanogr. 54, 1306-1322. https://doi.org/10.4319/lo.2009.54.4.1306

Ruecas, A., Brockmann, C., Stelzer, K., Tilstone, G., Beltran-Abaunza, J.., 2014. DUE CoastColour Validation Report (No. v1.0). Brockmann Consult.

Schroeder, T., Schaale, M., Fischer, J., 2007. Retrieval of atmospheric and oceanic properties from MERIS measurements: A new Case-2 water processor for BEAM. Int. J. Remote Sens. 28, 5627-5632. https://doi.org/10.1080/01431160701601774 
Schwefel, R., Gaudard, A., Wüest, A., Bouffard, D., 2016. Effects of climate change on deepwater oxygen and winter mixing in a deep lake (Lake Geneva): Comparing observational findings and modeling. Water Resour. Res. 52, 8811-8826. https://doi.org/10.1002/2016WR019194

Sharples, J., Moore, M.C., Rippeth, T.P., Holligan, P.M., Hydes, D.J., Fisher, N.R., Simpson, J.H., 2001. Phytoplankton distribution and survival in the thermocline. Limnol. Oceanogr. 46, 486-496. https://doi.org/10.4319/lo.2001.46.3.0486

Simpson, J.J., Stitt, J.R., 1998. A procedure for the detection and removal of cloud shadow from AVHRR data over land. IEEE Trans. Geosci. Remote Sens. 36, 880-897.

Sommer, U., Adrian, R., De Senerpont Domis, L., Elser, J.J., Gaedke, U., Ibelings, B., Jeppesen, E., Lürling, M., Molinero, J.C., Mooij, W.M., van Donk, E., Winder, M., 2012. Beyond the Plankton Ecology Group (PEG) Model: Mechanisms Driving Plankton Succession. Annu. Rev. Ecol. Evol. Syst. 43, 429-448. https://doi.org/10.1146/annurev-ecolsys110411-160251

Steissberg, T.E., Hook, S.J., Schladow, S.G., 2005. Characterizing partial upwellings and surface circulation at Lake Tahoe, California-Nevada, USA with thermal infrared images. Remote Sens. Environ. 99, 2-15. https://doi.org/10.1016/j.rse.2005.06.011

Taylor, J.R., Ferrari, R., 2011. Shutdown of turbulent convection as a new criterion for the onset of spring phytoplankton blooms. Limnol. Oceanogr. 56, 2293-2307.

Troitskaya, E., Blinov, V., Ivanov, V., Zhdanov, A., Gnatovsky, R., Sutyrina, E., Shimaraev, M., 2015. Cyclonic circulation and upwelling in Lake Baikal. Aquat. Sci. 77, 171-182.

Watanabe, S., Vincent, W.F., Reuter, J., Hook, S.J., Schladow, S.G., 2016. A quantitative blueness index for oligotrophic waters: Application to Lake Tahoe, California-Nevada. Limnol. Oceanogr. Methods 14, 100-109. https://doi.org/10.1002/lom3.10074

Wilson, R.C., Hook, S.J., Schneider, P., Schladow, S.G., 2013. Skin and bulk temperature difference at Lake Tahoe: A case study on lake skin effect. J. Geophys. Res. Atmospheres 118, 10,332-10,346. https://doi.org/10.1002/jgrd.50786

Wynne, T.T., Stumpf, R.P., Tomlinson, M.C., Fahnenstiel, G.L., Dyble, J., Schwab, D.J., Joshi, S.J., 2013. Evolution of a cyanobacterial bloom forecast system in western Lake Erie: Development and initial evaluation. J. Gt. Lakes Res. 39, 90-99. 


\section{Figure legends}

703 Figure 1. Differences of chlorophyll (CHL) and lake surface water temperature (LSWT) relative 704 to their spatial averages for two same-day scenes, one in spring and one in autumn 2011. Both 705 show a positive spatial correlation between CHL and LSWT.

706

707

708

709

710

711

712

713

714

715

716

717

718

719

720

721

722

723

724

725

726

727

728

729

730

731

732

733

734

735

736

Figure 2. Map of Lake Geneva with locations SHL2 (pink), Buchillon (green) and Pully (yellow). In-situ CHL calibration samples are regularly taken at SHL2. Temperatures measured at Buchillon and at SHL2 have been used for calibrating the three-dimensional Delft3D-Flow model. $20 \mathrm{~m}$ isolines are shown.

Figure 3. Concentrations of CHL during the productive season (March to October) in Lake Geneva. The data shown is based on bi-monthly in-situ measurements at position SHL2 (Figure 2) for the period 2002-2012. Boxplot with whiskers length $1.5( \pm 2.7 \sigma)$; outliers are not shown.

Figure 4. a) Average annual cycle of phosphate concentrations at different depths (0-5 m, $35 \mathrm{~m}$, $50 \mathrm{~m}, 100 \mathrm{~m}$ ) for the time 2002 to 2010 . Dashed line: average per day of the year; solid line: five data points running mean (corresponding to 12 days). b) Average annual cycle of LSWT, computed from AVHRR satellite images (2002-2012) and averaged over the whole lake. Dashed line: average per day of the year; solid line: 10 days running mean.

Figure 5. Workflow for the post-processing of the remote sensing images (CHL above; LSWT below) and the setup of the CHL-LSWT pairs of the images.

Figure 6. Ratio of the number of positive and negative Moran's I results (4 NN) per month (Xaxis) for different temporal offsets. The dotted line $($ ratio $=1)$ indicates equal numbers.

Figure 7. Moran's I for 4 to 440 NN. Dates correspond to those of Figures 9 and 10.

Figure 8. Bin averaged (every 0.1) absolute Moran's $I$ as a function of the wind ratio. Wind ratio is defined as the ratio between the wind averaged over the three day prior to the satellite image to the wind averaged over ten years. High Moran's I in summer are associated with high winds.

Figure 9. a) Wind magnitude and direction. Shaded area represent the investigated day with LSWT and CHL satellite data. b) CHL satellite image for 21 March 2011 (left) and 22 March 2011 (right). c) LSWT satellite image for 21 March 2011 (left) and 22 March 2011 (right). d) LSWT model data for 21 March 2011 (left) and 22 March 2011 (right). e) Wind magnitude (colour-coded) and direction (arrows) for 20 March 2011. f) Longitudinal transect of temperature over the water column for day 20 March 2011.

Figure 10. a) Wind magnitude and direction. Shaded area represent the investigated day with LSWT and CHL satellite data. b) CHL satellite image for 30 August 2011 (left) and 09 September 2011 (right). c) LSWT satellite image for 30 August 2011 (left) and 09 September 2011 (right). d) LSWT model data for 30 August 2011 (left) and 09 September 2011 (right). e) modelled thermocline depth for 30 August 2011 (left) and 09 September 2011 (right). j) 
737 Longitudinal transect of temperature over the water column for day 08-09-2011. f) - i) same as b)

738 - e) but for the days 10 September 2011 (left) and 13 September 2011. k) Time series of in-situ

739 (red line, $1 \mathrm{~m}$ depth; black line, $36 \mathrm{~m}$ depth), modelled temperature (blue line, $1 \mathrm{~m}$ depth),

740 remotely sensed LSWT (green dots).

741 Figure 11. Detrended model temperature time series at $20 \mathrm{~m}$ depth on three control points across

742 the lake. Data have been offset vertically by $5{ }^{\circ} \mathrm{C}$ (East control point) and $10{ }^{\circ} \mathrm{C}$ (North control

743 point). The $\sim 3.5$-day oscillation corresponds to a Kelvin wave with cyclonic propagation along

744 the shore.

745

746 


\section{Appendix A}

\section{Data sources and hydrodynamic lake model}

We used the Delft3D-Flow as three-dimensional (3D) hydrodynamic model with a k- $\varepsilon$ turbulence closure. River inflows and outflows were not implemented in this study and the

751 752

753

754 755 756
66 forcing was solely at the air-water interface. The forcing data includes wind intensity and direction, solar radiation, air temperature, cloud coverage, relative humidity and atmospheric pressure provide at hourly time steps from a meteorological model COSMO-2. For this study, only wind forcing was treated as a space varying parameter and all other forcings were extracted from a grid cell in the middle of the lake. The model constant used in the model are summarized in Table A1.

For the year 2011, we have validated the model with bi-monthly temperature profile at the lake center (SHL2), hourly temperature measurements at $1 \mathrm{~m}$ and $36 \mathrm{~m}$ below the surface offshore Buchillon (Figure 2), 297 AVHRR LSWT data (with cloud cover lower than 50\%) and acoustic Doppler current profilers. Figure A1 provides an overview of the validation and the different root mean square errors are indicated in Table A2.

From a lake functioning perspective, a better integration of in-situ and remotely sensed observation into models, for instance, through data assimilation, will provide better estimates of the parameters over time and, more importantly, a quantification of uncertainties. 


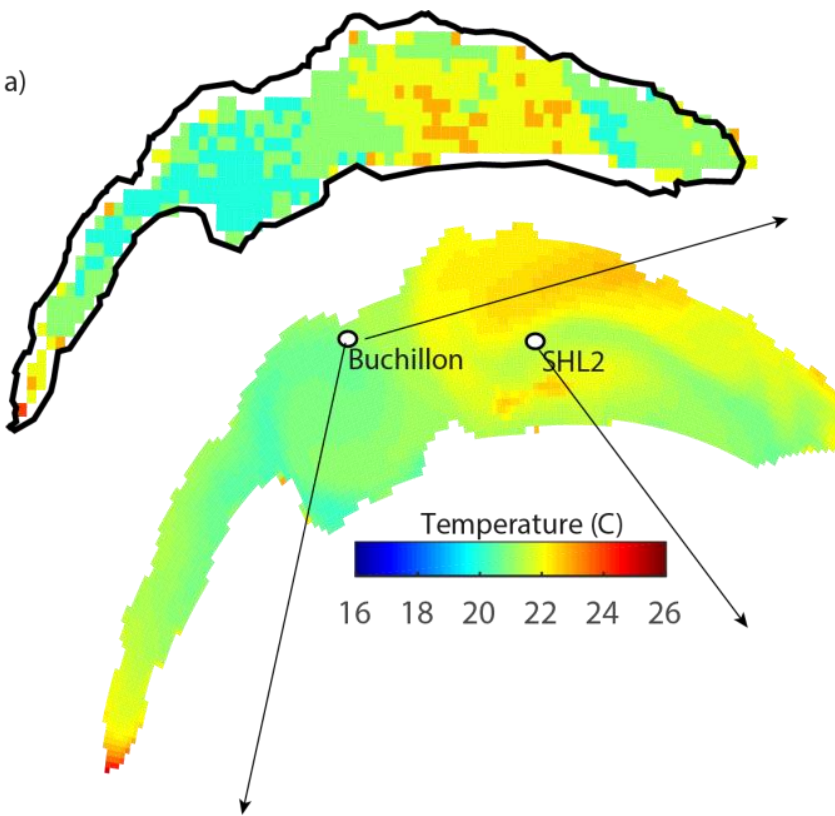

b)

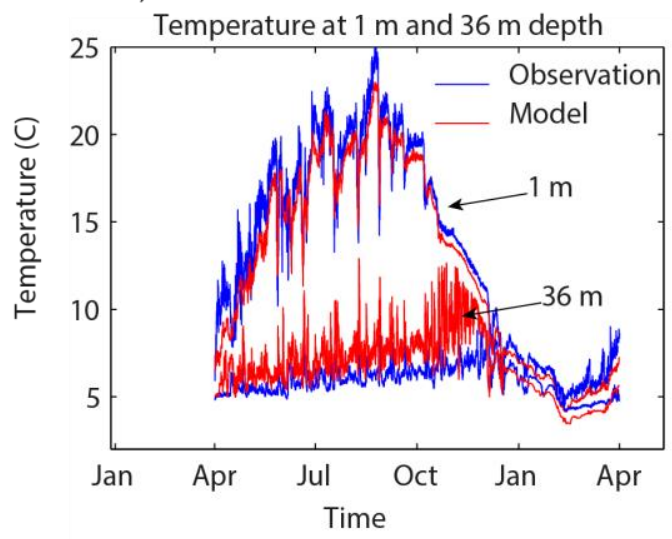

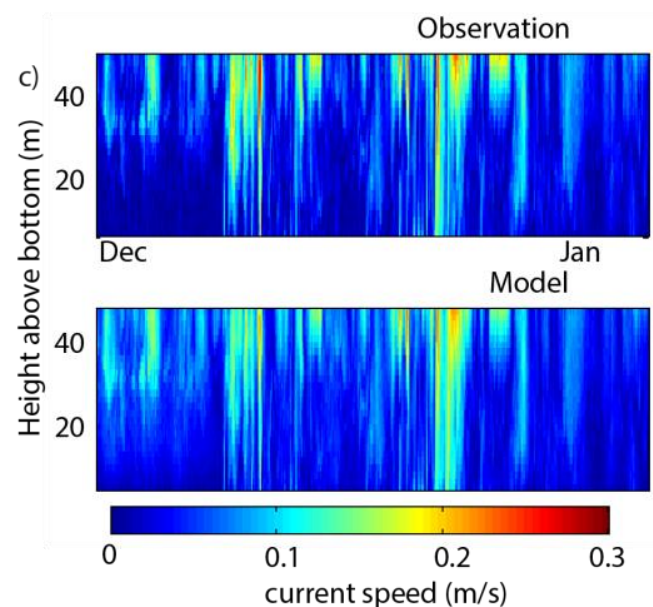

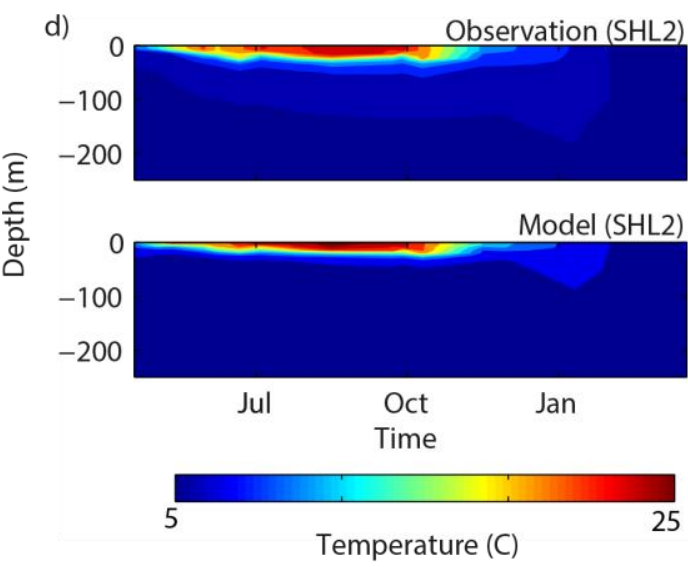

768

769

770

771

772

773

774

775

776

Figure A1. Examples of validation of the model. a) Comparison between the AVHRR LSWT and the model LSWT on day 5 July 2011. The horizontal structures are reproduced by the model. Other comparisons can be found on Figs. 9-10. b) Time series of observed and modelled temperature at $1 \mathrm{~m}$ and $36 \mathrm{~m}$ below the surface offshore of Buchillon. $\mathrm{c}$ ) Time series of observed and modelled current intensity. d) Bi-weekly time series of observed and modelled temperature at the lake center. RMSE are provided on Table A2.

6 Table A1: Parameters used in the three-dimensional hydrodynamic model.

\begin{tabular}{|l|l|l|}
\hline Parameter & Name & Value \\
\hline$v_{H}\left[\mathrm{~m}^{2} \mathrm{~s}^{-1}\right]$ & Background horizontal eddy viscosity & 1.0 \\
\hline$v_{V}\left[\mathrm{~m}^{2} \mathrm{~s}^{-1}\right]$ & Background vertical eddy viscosity & 0 \\
\hline
\end{tabular}




\begin{tabular}{|l|l|l|}
\hline$D_{H}\left[\mathrm{~m}^{2} \mathrm{~s}^{-1}\right]$ & Background horizontal eddy diffusivity & 1.0 \\
\hline$D_{V}\left[\mathrm{~m}^{2} \mathrm{~s}^{-1}\right]$ & Background vertical eddy diffusivity & $5.0 \times 10^{-7}$ \\
\hline$z_{S e c}[\mathrm{~m}]$ & Secchi depth & 5 \\
\hline$k_{S}[\mathrm{~m}]$ & Bottom roughness & $5.0 \times 10^{-2}$ \\
\hline$c_{H}[-]$ & Stanton number & $5.0 \times 10^{-3}$ \\
\hline$c_{e}[-]$ & Dalton number & $1.5 \times 10^{-6}$ \\
\hline
\end{tabular}

777

778 Table A2: RMSE between observation and model.

\begin{tabular}{|l|l|l|l|l|l|}
\hline Location & SHL2 & Buchillon & Buchillon & Entire Lake & Buchillon \\
\hline Deployment & $\begin{array}{l}\text { Multiparameter } \\
\text { probe (water } \\
\text { column) }\end{array}$ & $\begin{array}{l}\text { Mooring } \\
(1 \mathrm{~m})\end{array}$ & $\begin{array}{l}\text { Mooring }(36 \\
\mathrm{m})\end{array}$ & $\begin{array}{l}\text { Satellite } \\
(\text { surface })\end{array}$ & $\begin{array}{l}\text { ADCP } \\
\text { mooring } \\
(\text { water } \\
\text { column })\end{array}$ \\
\hline Parameter & Temperature & Temperature & Temperature & Temperature & $\begin{array}{l}\text { Current } \\
\text { velocity }\end{array}$ \\
\hline Units & $\left({ }^{\circ} \mathrm{C}\right)$ & $\left({ }^{\circ} \mathrm{C}\right)$ & $\left({ }^{\circ} \mathrm{C}\right)$ & $\left({ }^{\circ} \mathrm{C}\right)$ & $\left(\mathrm{m} \mathrm{s}^{-1}\right)$ \\
\hline RMSE & 1.9 & 0.7 & 1.1 & 1.5 & 0.05 \\
\hline
\end{tabular}

779

780 
781

782

783

784

785

786

787

788 789

790

791

792

793

794

795

796

797

798

799

800 801 here.

802

803

804

805

806

\section{Appendix B}

\section{Spatial correlation without temporal offset}

The analysis of CHL and LSWT pairs with low average CHL concentrations $\left(<6 \mathrm{mg} \mathrm{m}^{-3}\right.$, first graph of Figure B1, all NN and 0 offset) indicates slightly positive average Moran's I in early spring and negative between May and October. The average Moran's I for data pairs representing intermediate CHL ( 6 to $12 \mathrm{mg} \mathrm{m}^{-3}$ ) indicates a strong positive correlation in March, but no clear temporal patterns for the following months. In contrary, high CHL data pairs (CHL $>12 \mathrm{mg} \mathrm{m}^{-3}$ ), reveal a consistently decreasing average Moran's I in the course of the year.

\section{Spatial correlation with temporal offset}

The monthly averages of Moran's I are more pronounced for data pairs with one or two days of difference (i.e. LSWT preceding CHL; Figure B1, D)-F)). The reaction of the phytoplankton on nutrient concentration variations may be better captured after some temporal offset, even for low CHL average concentrations. Again, Moran's I is decreasing between spring and summer from positive correlation in spring to negative correlation in summer. The signal is again generally stronger for higher CHL concentrations (Figure B1, D), $3^{\text {rd }}$ graph). The effect of the spatial extent of the included NN on the correlation, however, is not homogenous anymore ( $2^{\text {nd }}$ graph of E) and F), Figure B1). It appears that for a certain temporal offset between CHL and LSWT, the spatial extent of the phenomenon decreases. Whereas for same-day data pairs the results between different NN numbers were very similar, considerable differences are found

For three and four days of difference between the LSWT and the CHL data and low CHL content (Figure B1, G)), the evolution during the productive season is similar to the previous results. Positive values are found for March and April, after which the values become negative but stay close to zero. Just like for data with one to two days between LSWT and CHL observations, differences are found between small and large spatial extents $(\mathrm{H})$ and $(\mathrm{I})$. 


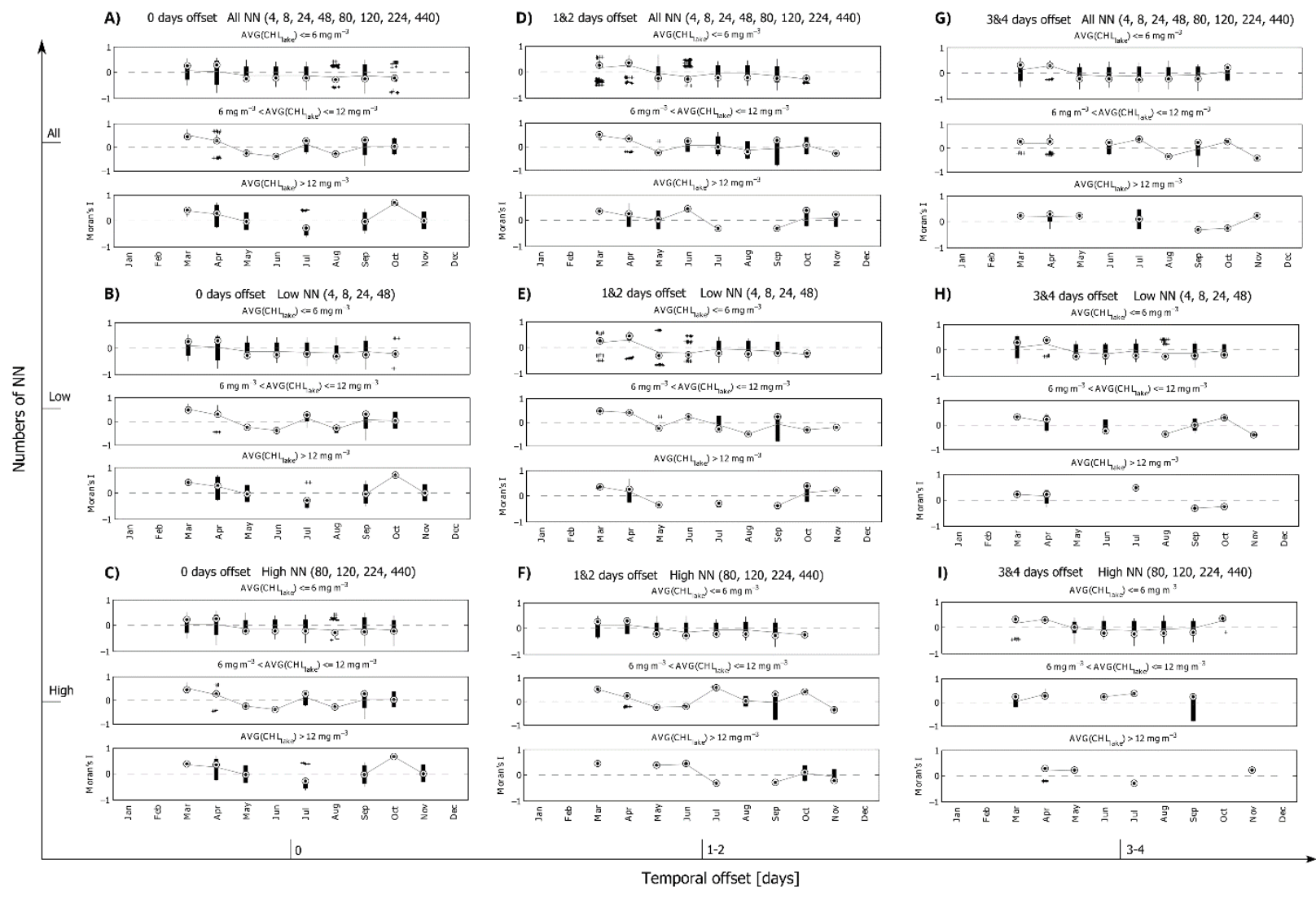

Temporal offset [days]

808 Figure B1. Boxplots showing all results of Moran's I of LSWT and CHL image pairs, with 809 different temporal offsets on the $x$-axis ( 0 days, $1 \& 2$ days, $3 \& 4$ days) as well as different 810 spatial extents on the $y$-axis (all NN, low NN and high NN). 